\title{
Location and head direction representation in the dorsal striatum of rats
}

\author{
SHERI J. Y. MIZUMORI, KATHARINE E. RAGOZZINO, and BRENTON G. COOPER \\ University of Utah, Salt Lake City, Utah
}

\begin{abstract}
The activity of dorsal striatal location and head direction neurons were recorded as rats performed a hippocampal-dependent spatial working memory task. Relative to previous descriptions of hippocampal fields, striatal fields appeared more dependent on the visual environment in which the maze was performed. Striatal head direction correlates were also shown to be dependent upon the visual context in a lit environment: The directional preferences rotated with the rotation of distal visual cue, and maze or rat rotations had no effect. However, when animals performed the maze in darkness, idiothetic information gained greater control over head direction preferences: Passive movement of the rat in darkness (but not in light) disrupted directional firing. During both light and dark trials, the same head direction preferences were observed. A special contribution of the dorsal striatum to navigation may be to facilitate an animal's ability to switch between navigational strategies, thereby maintaining behavioral constancy in changing environments.
\end{abstract}

The basal ganglia traditionally have been considered to be primarily involved in motor control. This view was supported by clinical observations that basal ganglia diseases, such as Parkinson's disease, result in profound motor deficits. This classic motor interpretation was also supported by animal lesion data showing prominent motor dysfunction following basal ganglia ablation, as well as by neurophysiological evidence that portions of the basal ganglia are topographically activated during specific skeletal movements (e.g., Crutcher \& Alexander, 1990). Other findings, however, suggest a more heterogeneous functional contribution of the basal ganglia (especially of the striatum) to behavior. Anatomical findings regarding the striato-thalamo-cortical circuit (e.g., Groenewegen \& Berendse, 1994; McGeorge \& Faull, 1989; Swanson \& Kohler, 1986) suggest that the striatum may importantly influence cognitive functions such as planning and coordinating the execution of complex movement patterns, as well as working memory and attention. Indeed, Parkinson's patients reveal impairments in context-based behavioral planning, perhaps indicating difficulty in reorganizing behavior according to new task requirements (see, e.g., Cools, van den Bercken, Horsink, Spaendonck, \& Berger, 1984; Downes et al., 1989). Also, select portions of striatum become metabolically activated during working memory task performance (Levy, Fried-

This work was supported by NSF Grants IBN9514880 (S.J.Y.M.) and DGE9616182 (K.E.R.), and NIH Grants MH58755 (S.J.Y.M.) and MHI 1998 (B.G.C.). We thank James Canfield for comments and suggestions throughout this study, Stefan Leutgeb for invaluable programming contributions and comments on the manuscript, and Karen Burk, Rebecca Green, Annette Lavoie, and Wayne Pratt for much appreciated assistance with data acquisition and analysis. Correspondence should be addressed to S. J. Y. Mizumori. Department of Psychology. Box 351525. University of Washington. Seattle. WA 98195 (e-mail: mizumori@ u.washington.edu). man, Davachi, \& Goldman-Rakic, 1997). Finally, lesion studies in cat, monkey, and rat show that different corticostriatal systems may subserve different forms of learning (see, e.g., Devan \& White, 1999; Divac, Markowitsch, \& Pritzel, 1978; Divac, Rosvold, \& Szwarcbart, 1967; Hauber \& Schmidt, 1994).

The consequences of lesions to the dorsal striatal (or the caudate-putamen complex) in rodents are generally consistent with the view that the lateral dorsal striatum subserves simple stimulus-response learning and sensorimotor functions (Dunnett \& Iversen, 1982; Reading, Dunnett, \& Robbins, 1991). In contrast, lesions of the medial dorsal striatum often result in deficient performance on tasks requiring allocentric spatial processing (Devan, Goad, \& Petri, 1996; Devan \& White, 1999; Whishaw, Mittleman, Bunch, \& Dunnett, 1987). The latter findings are somewhat controversial, however, since other reports describe no impairment in spatial learning following dorsal striatal lesions (e.g., Cook \& Kesner, 1988; Kesner, Bolland, \& Dakis, 1993). Devan and White have suggested that one source of the apparent discrepancy is that studies reporting no spatial deficits tend to involve lateral striatal lesions, while spatial deficits are more readily observed following medial striatal lesions. This view was expanded in a different study by the same authors (Devan, McDonald, \& White, 1999). They tested the effects of medial or lateral dorsal striatal lesions on performance during the hidden and visible platform versions of the water maze task. As before (Devan \& White, 1999), they found that medial, and not lateral, striatal lesions produced a significant learning deficit. Medial striatal lesioned rats, however, eventually learned the task as well as controls. When rats were asked to effectively select from competing spatial or cue strategies, medial, but not lateral, striatal lesioned rats showed enhanced preference for using the cue strategy. These authors reasoned that 
more pronounced spatial deficits might be observed after medial dorsal striatal lesions in test situations that present more than one solution because alternate behavioral strategies "win the competition." In this sense, then, dorsal striatal lesions do not impair spatial memory per se, as has been argued for hippocampus (e.g., Barnes, 1988). Rather, as has been suggested by Wise, Murray, and Gerfen (1996), dorsal striatum may provide frontal cortex with information that ultimately helps frontal cortex to produce appropriate response strategies that guide future behaviors. To accomplish this function, information defining the current context (which can be broadly defined as the existing sensory environment) needs to be represented in basal ganglia.

A significant role for contextual information in striatal function has been shown by primate neurophysiological work. For example, Hikosaka and Wurtz (1983) described memory-related activity in the pars reticulata of the substantia nigra, as well as for caudate (Hikosaka, Sakamoto, \& Usui, 1989). Striatal neuron discharge seems to be evoked by the "expectation" of events rather than a specific behavioral act. Factors that contribute to the (neural) expectation response include not only whether an event is going to occur, but also the location of the event or target stimulus (Hikosaka et al., 1989), as well as the direction of impending movement (Alexander \& Crutcher, 1990). Also, caudate unit firing depends more on the context in which actions occur than on the specific response of the animal (e.g., Gardiner \& Kitai, 1992; Kimura, 1990; Rolls, Thorpe, \& Maddison, 1983; Schultz, Apicella, Romo, \& Scarnati, 1995; Schultz \& Romo, 1992). That is, movement- and reward-related firing are observed only in the context of the task environment, and not when animals exhibit the same movement elsewhere. These context-dependent unit changes develop over time with new learning (Tremblay, Hollerman, \& Schultz, 1998).

The existing, but sparse, rodent in vivo physiological data are generally congruent with those from primates: The extent of neural activation in rat dorsal striatum following explicit auditory stimulation is not as large as the known auditory corticostriate projection (Arnauld, Jeantet, Arsaut, \& Demotes-Mainard, 1996). Similarly, although the anatomical projections are widespread, somatosensory stimulation in rat activates only a subset of the entire anatomical field, suggesting that different behavioral contexts could elicit only relevant sensory fields (L. L. Brown, Feldman, Divac, Hand, \& Lidsky, 1994; L. L. Brown, Hand, \& Divac, 1996). Consistent with the view that the striatum neural code reflects the behavioral context, Wiener (1993) showed that rat dorsal striatal neurons exhibit location-specific and directional headingrelated firing, correlates typically associated with hippocampal (context-dependent) systems.

In the present study, we sought first to replicate the initial findings of spatial representation in dorsal striatum reported by Wiener (1993). A replication would strengthen the hypothesis that the striatum processes spatial context information. Next we tested the hypothesis that if dorsal striatal spatial information is derived from limbic spatial processing, the spatial representations found in dorsal striatum might show response properties similar to hippocampal neurons when animals are tested on a hippocampaldependent behavioral task. Single unit activity of location and head direction cells in dorsal striatum were recorded as rats performed a spatial working memory task. The recording electrodes targeted the medial dorsal striatum since our preliminary work indicated that there is a higher proportion of head direction cells in the medial, rather than lateral, striatum. Also, lesion studies (described above) suggest there may be a bias for the medial dorsal striatum to process spatially relevant information. Various manipulations of the sensory environment were performed to test the context sensitivity of the recorded cells.

\section{METHOD}

\section{Subjects}

Dorsal striate unit-behavioral correlates were assessed from 23 mature adult male rats that were 11-15 months of age at test ( 16 Fischer-344 rats, 5 Long-Evans rats, and 2 Fischer $X$ Brown Norway rats). In addition, data were included from 2 Fischer $X$ Brown Norway hybrid rats that were 27 months old. According to (unpublished) results from this laboratory and others (Ray Kesner, personal communication), the latter animals do not show age-related behavioral impairment at this age when tested in spatial tasks similar to the one used here. All animals were housed individually with restricted access to food during testing, and free access to water throughout. The rooms were automatically controlled in terms of temperature and humidity. Lights were on in the colony room from 7 a.m. to 7 p.m. Behavioral testing occurred during the light phase of the day:night cycle. All animal handling procedures were in compliance with NIH guidelines.

\section{Behavioral Apparatus}

All animals were trained to perform a spatial working memory task on an eight-arm radial maze before the surgical implantation of recording electrodes (similar to procedures described by Mizumori \& Williams, 1993). Briefly, the elevated maze consists of eight alleys or arms $(58 \times 5.5 \mathrm{~cm})$ that radiate from a round central platform (19.5-cm diameter). Each arm is hinged so that the proximal half can be either raised (so that it is flush with the central platform) or lowered (to restrict access to that arm from the center). Presentation of individual arms is accomplished by remote control. The maze is situated within a canopy-style black curtained environment that extends from ceiling to floor (Cooper, Miya, \& Mizumori, 1998). The restricted maze environment was illuminated by four $15-\mathrm{W}$ incandescent lights evenly spaced around the top of the curtain wall. Distinct visual cues (posters) were placed within the curtained environment. The average illumination when the four lights were on was 3.0 lux. For some tests, rats performed trials with the lights turned off. In that condition, our light meter registered 0.00 lux. Our camera is sensitive to illumination of $0.5 \mathrm{lux}$ (which is below threshold for detection by rats; Silver, 1967) or greater. Our camera detected no visible light when the room lights were off. Finally, since the diode(s) used were infrared, and rats are visually insensitive to infrared illumination, we assume that the diodes did not serve as a light source during dark trials.

\section{Behavioral Training}

Nine rats tested were trained to obtain one drop of chocolate milk placed at the end of each maze arm. To test whether cells were sen- 
sitive to the locations of rewards of different magnitudes, the remaining animals received five drops of chocolate milk for entering arms $0,2,4$, and 6 , and one drop of chocolate milk for entering arms $1,3,5$, and 7 . For all animals, unless otherwise indicated, the locations of the large and small rewards were constant. Also, regardless of the reward contingencies, accurate performance reflected the same spatial working memory requirement (see memory phase below): During pretraining, an animal was placed on the maze center and allowed to roam freely for about $15 \mathrm{~min}$. When an animal readily entered a maze arm and consumed the reward, the training phase began: Four arms were presented to the rats individually and sequentially (study phase). Upon return to the center platform following entry into the fourth maze arm, all eight arms were presented simultaneously, and the animal was allowed to select the remaining rewards (memory phase). This partial forced-choice procedure was used to reduce the likelihood that the rats might adopt a stereotyped response strategy for solving the task (Mizumori, McNaughton, Barnes, \& Fox, 1989; Mizumori, Perez, Alvarado, Barnes, \& McNaughton, 1990). Furthermore, this procedure prevented rats from preferentially selecting high-reward arms early in the trial. During the first four choices of the memory phase, however. rats do tend to select the remaining high-reward arms before low-reward arms (Pratt \& Mizumori, 1998), indicating that the animal distinguishes the differences in reward magnitudes used here. The experimenter always verified reward consumption. If an animal entered an arm already selected during that trial, an error was recorded. A trial ended when the rat obtained all eight rewards. During the subsequent 2-min intertrial interval, the rat was confined to the maze center as the experimenter rebaited the arms for the next trial. When a rat had performed 15 daily trials for 7 days, free access to food was permitted for 2-3 days. After this time the recording electrodes were surgically implanted. Following 7 days of recovery from surgery, maze training resumed. For a subset of cells, the behavioral correlates were tested in terms of their sensitivity to changes in visual context by extinguishing room lights. Specific details are described in the results sections that are relevant to these tests.

\section{Surgical Procedure and Electrode Construction}

Animals were initially anesthetized with $30 \mathrm{mg} / \mathrm{kg}$ Nembutal $(50 \mathrm{mg} / \mathrm{ml})$, and supplements of $0.5 \mathrm{ml}$ were administered as needed to keep the animal in a deeply anesthetized state. Following application of the antibacterial agent Betadine to the scalp, an incision was made to expose the skull. Small burr holes were drilled to permit positioning the recording electrodes within the following coordinates (Paxinos \& Watson, 1986; Swanson, 1992): A-P 1.7 to $-0.8 \mathrm{~mm}$ relative to Bregma, $\mathrm{L} \pm 1.5$ to $2.0 \mathrm{~mm}$ relative to midline, and $D-V 2.0$ below the brain surface. Each recording stereotrode consisted of two lacquer-coated tungsten wires (23- $\mu \mathrm{m}$ diameter) that were twisted together, dipped in Epoxylite, then baked. The tips were cut blunt, then gold-plated to give final impedances of $50-150 \mathrm{k} \Omega$ (tested at $1 \mathrm{kHz}$ ). Individual stereotrodes were threaded through a 30 -gauge stainless steel tube that was mounted on a movable microdrive that allows the stereotrode to be advanced in about $22-\mu \mathrm{m}$ increments.

A reference electrode (114- $\mu \mathrm{m}$ diameter Teflon-coated stainless steel wire) was placed in posterior corpus callosum, and a ground lead was soldered to a jeweler's screw that was secured to the skull. Amphenol pins were connected to the electrodes, and a ground screw and amphenol pins were inserted into one or two connecting sockets permanently attached to the animal's head. The socket was later connected to a headstage for recording. If necessary, the wound was closed with silk suture. Bicillin L-A $(0.1 \mathrm{ml}$ of 300,000 units $/ \mathrm{ml}$ solution) was injected intramuscularly into each hindlimb to prevent infection. Following surgery animals were monitored continuously until they could move about in a coordinated fashion.

\section{Single-Unit and Behavioral Monitoring}

After animals achieved postoperative maze training criterion (i.e., performed 15 trials daily for 7 consecutive days), the stereotrodes were slowly advanced until well-isolated units were encountered, or until they were lowered a maximum of about $120 \mu \mathrm{m}$ per day. While an animal was checked for unit activity, it remained on the central platform of the maze, without access to the arms.

The stereotrode recording technique is fundamentally similar to the one used in prior studies (e.g., McNaughton, O'Keefe, \& Barnes, 1983; Mizumori \& Williams, 1993). This procedure facilitates confident unit isolation by making use of the ratios of spike characteristics recorded on the two recording channels ( $\mathrm{X}$ and $\mathrm{Y}$ ). Incoming signals are amplified $(5-10 \mathrm{~K})$, filtered between $600 \mathrm{~Hz}$ and $6 \mathrm{kHz}$, and then passed through a window discriminator so that a sampling period $(1 \mathrm{msec})$ begins when the signal from $\mathrm{X}$ or $\mathrm{Y}$ exceeds a preset threshold. Single units were first identified aurally (with the aid of an audio monitor) and visually (with the aid of an oscilloscope). When the experimenter determined that the signals were of sufficient clarity (e.g., had a signal-to-noise ratio of at least $3: 1$ ), the signals were transmitted via the Discovery routine (DataWave, Inc.) to an AST-386 or a BNW IC-90 (Pentium-based) computer system (sampling frequency: $32 \mathrm{kHz}$ per channel). The experimenter was then able to use a highly interactive cluster analysis program that divides the multidimensional experimenter-defined parameter space into areas corresponding to individual spike generators. Since each analog trace is saved digitally on computer in its entirety, a templatematching program was also used to further isolate a single waveform type from others that might occupy the same cluster parameter space. This spike separation routine was performed before the recording session so that the experimenter could verify the accuracy of the cluster cutting by comparing the units identified by the DataWave system with units detected on the oscilloscope and audio monitor.

For 22 rats, a headstage that comprised five to seven FET (unity gain) preamplifiers and a light-emitting diode was attached to a connecting socket on the rat's head. Each rat had a 9-pin connecting socket implanted, and the dorsal striatum recordings were made first in one hemisphere (usually, but not always, the right hemisphere). The recorded hemisphere was then disconnected and the second hemisphere connected to the socket so that recordings could be made from the second hemisphere. For 3 other rats, the headstage contained two diode arrays. The Dragon Tracker system distinguished the front and back diode arrays on the basis of size: The large array was positioned about $10 \mathrm{~cm}$ above the rat's nose, and a small array was placed about $19 \mathrm{~cm}$ caudal to the large array. The large diode indicated the rat's current position, while directional heading was calculated by comparing the angle of the back diode relative to the front diode array. The spatial resolution of the tracker system (about $0.53 \mathrm{~cm}$ ) was determined by fitting the maze within a $256 \times 256$ pixel array. The diode assembly was connected to an $18-$ pin connector that could be fastened to the rat's electrode implant. During a recording session, the position of the animal was monitored automatically with a Dragon Tracker system (Boulder, CO). Position data were acquired by identifying the location of the single diode (of the single diode headstage) or the front diode array (of the double diode headstage) in the pixel array (which covered the area of the maze). The sampling frequency of position data was $20 \mathrm{~Hz}$.

\section{Data Analysis}

To permit more direct comparison with published data on properties of place neurons recorded in other brain regions (e.g., Knierim, Kudrimoti, \& McNaughton, 1995; Lavoie \& Mizumori, 1994; Markus, Barnes, McNaughton, Gladden, \& Skaggs, 1994; Markus et al., 1995; Mizumori et al., 1989; Mizumori, Ward, \& Lavoie, 1992), all cells recorded in dorsal striatum were evaluated for locationspecific firing according to measures described in other studies. For 
all of the measures, data collected during the intertrial interval were not included in the analysis. Spatial specificity scores were determined by calculating 16 rates: one for each direction of movement (inward and outward) on each of the eight maze arms. The highest rate was divided by the mean of the remaining 15 rates (McNaughton, Barnes, \& O'Keefe, 1983). As in past studies (e.g., Mizumori et al., 1992), cells with spatial selectivity scores greater than or equal to 1.7 were classified as location cells. To ensure that the spatial selectivity score did not reflect spurious discharge, a location field reliability (defined below) of greater than 0.25 was also required. Furthermore, given the suggestion that the basal ganglia might encode velocity rather than visual spatial aspects of behavior (Maguire et al., 1998), we correlated velocity of movement on each maze arm (for both inward and outward movement directions) with the 16 rates that were incorporated into the specificity analysis.

While the above measure has been used to quantify spatial selectivity of location-selective cells, it may be misleading when used to quantify broad location fields. Therefore, we also quantified spatial specificity by using an information content measure that is independent of field size. Using this measure, other investigators (Knierim et al., 1995; Markus et al., 1995; Taube, 1995b) have quantified location-selective discharge in terms of the quantity of location-specific information relayed by individual spikes of a cell (Skaggs, McNaughton, Gothard, \& Markus, 1993). Functionally, such an information content score reflects how well the firing rates of cells predict an animal's location. To calculate information content scores, data were first binned into a $64 \times 64$ array. Information content (IC) is defined as

$$
\mathrm{IC}=\Sigma P_{j}\left(R_{j} / R\right) \log _{2}\left(R_{j} / R\right),
$$

where, $P_{j}$ is the probability that a rat will occupy bin $j, R_{j}$ is the mean firing rate for $\operatorname{bin} j$, and $R$ is the mean firing rate across the entire maze.

In addition to the specificity of spatial information, we calculated the size of the location field of a cell, as well as the number of location fields shown by a given cell. The sum of the spikes in each bin in the $64 \times 64$ array was divided by occupancy time. Location fields were defined as continuous regions of at least 20 pixels that were associated with firing rates that were at least $1 S D$ above the mean firing rate for the cell, an algorithm often used to quantify hippocampal place fields (e.g., Hetherington \& Shapiro, 1997). This procedure seemed justified since the mean firing rate of the striatal location cells was comparable to that reported for hippocampal place cells (e.g., Barnes, McNaughton, Mizumori, Leonard, \& Lin, 1990; see results below), and both kinds of fields seem to approximate three-dimensional Gaussians with extended sampling. If the fields occupied adjacent bins on a given maze arm, they were combined. If a cell's field extended across two arms, each arm was considered to have its own field. The number of pixels within a defined location field determined the location field size. Since a number of dorsal striatum cells showed multiple location fields, the average number of fields was also determined. The largest location field for a cell was considered its major field, while the remaining fields were considered its minor fields. Included as minor fields were those whose areas were more than half the size of the major field.

Location fields can vary not only in terms of their size but also in terms of the reliability with which the location information is coded. Therefore, as described in many prior studies (e.g., Barnes et al., 1990; Mizumori et al., 1996), we calculated a reliability measure as the proportion of trials in which the cell fired maximally at the location of the major location field. A cell that fired consistently across trials at its highest rate in the primary field would have a high reliability score. Note that in theory, a given cell could receive a score of less than 1.00 even though it always fired when the rat traversed the cell's location fields. In this case, the cell may have also fired at a higher rate at other locations. Thus, a cell would receive a perfect reliability score of 1.00 only if the highest firing rate of the cell was exclusively and always associated with one location. The latter rarely happens, even for hippocampal place cells. Since location fields are usually smaller in size than the area of a maze arm, theoretically, a field could vary in its location on an arm and still be given a high reliability score. Given this, we developed a spatial covariance score to cross-validate the reliability measure. This score reflects the extent to which subsets of pixels are reliably associated with elevated firing rates across trials. Specifically, rate maps were generated independently for each trial. Each rate for a given location was entered as repeated observations into the statistical calculation of covariance (Hays, 1994). Thus, the covariance score describes a unit's tendency to repeatedly discharge in the same location during a sequence of trials.

A third spatial characteristic of dorsal striatum location neurons was the directional preference of the cell. Therefore, we compared the mean firing rate as the animal moved inward or outward on maze arms through the location field. Wiener (1993) described another type of directional code in the dorsal striatum: Three neurons in that study preferentially fired as a rat pointed its head in a particular direction in horizontal space, irrespective of the animal's location. This neural property appears to be analogous to the head direction cells found in other brain areas (Chen, Lin, Barnes, \& McNaughton, 1994; Chen, Lin, Green, Barnes, \& McNaughton, 1994; Mizumori \& Williams, 1993; Taube, 1995a; Taube, Muller, \& Ranck. 1990). In the present study, head direction selectivity of cells recorded with the single-diode headstage was determined by first calculating the mean rate of the cell as the animal traveled outward on the maze arms in each of the eight possible directions. The highest rate was divided by the mean of the remaining seven rates, resulting in a directional index that reflected the degree of directional selectivity.

Since a portion of these data were collected using a single-diode tracking system, issues may arise concerning our ability to determine the directional heading of the animals, and whether the putative dorsal striatum head direction neurons exhibit location independence. Regarding the first issue, the animals were highly trained, perhaps overtrained, on a task that essentially restricts which direction an animal can move. Thus, animals always moved outward on maze arms when the diode was observed to move outward on a maze arm. The directional selectivity score was based on the firing rate as rats traverse maze arms in the outward direction. Additional manipulations were conducted that, among other things, tested the location independence of head direction cells (e.g., passive movement tests; see Results section below). Briefly, the same directional preference for a cell was observed regardless of the animal's location. It is worth noting that analyses of dual-diode data have been directly compared with analyses obtained from single-diode recordings in the posterior parietal cortex (Chen, Lin, Green, et al., 1994): Using an almost identical task as the one used here, their initial classification of head direction cells based on single-diode recording was confirmed by subsequent double-diode recordings. The baseline pattern of discharge that we observed for cells classified as head direction cells (described below) is essentially identical to that described by Chen, Lin, Green, et al. using a comparable method. Furthermore, in the present study, recordings from three head direction cells using the double-diode recording method confirmed the location-independent, head direction nature of these cells (see Figures 6, 7, 9, and 10). In all tests, head direction cell responses were the same regardless of the tracking system used. However, the tuning functions of single-diode data tended to be slightly broader than tuning curves generated from double-diode data (see Figures 6,9 , and 10 for examples).

\section{RESULTS}

Similar to the results of Wiener (1993), spatial (location or heading direction) and movement behavioral correlates were readily observed for dorsal striatum neu- 
rons. In addition, we found neural correlates for reward, and for combinations of these categories. There were no strain or age differences for any of the measures reported below. Therefore, the data were combined into one group. Out of a total of 431 dorsal striatum neurons recorded, 187 cells $(43.4 \%)$ were categorized as one of the following correlate types: spatial, movement related to turns, forward movement, multiple movements, or a nonlocomotor state, reward, or combined correlate (e.g., turn-bylocation). There were 244 cells ( $56.6 \%$ of recorded cells) that did not meet any criteria for behavioral classification, and were thus classified as cells with no clear correlates.

Electrodes sampled a large extent of the anterior two thirds of the medial dorsal striatum. Figure 1 presents a schematic illustrating the recording sites at which cells with behavioral correlates were found. The present study

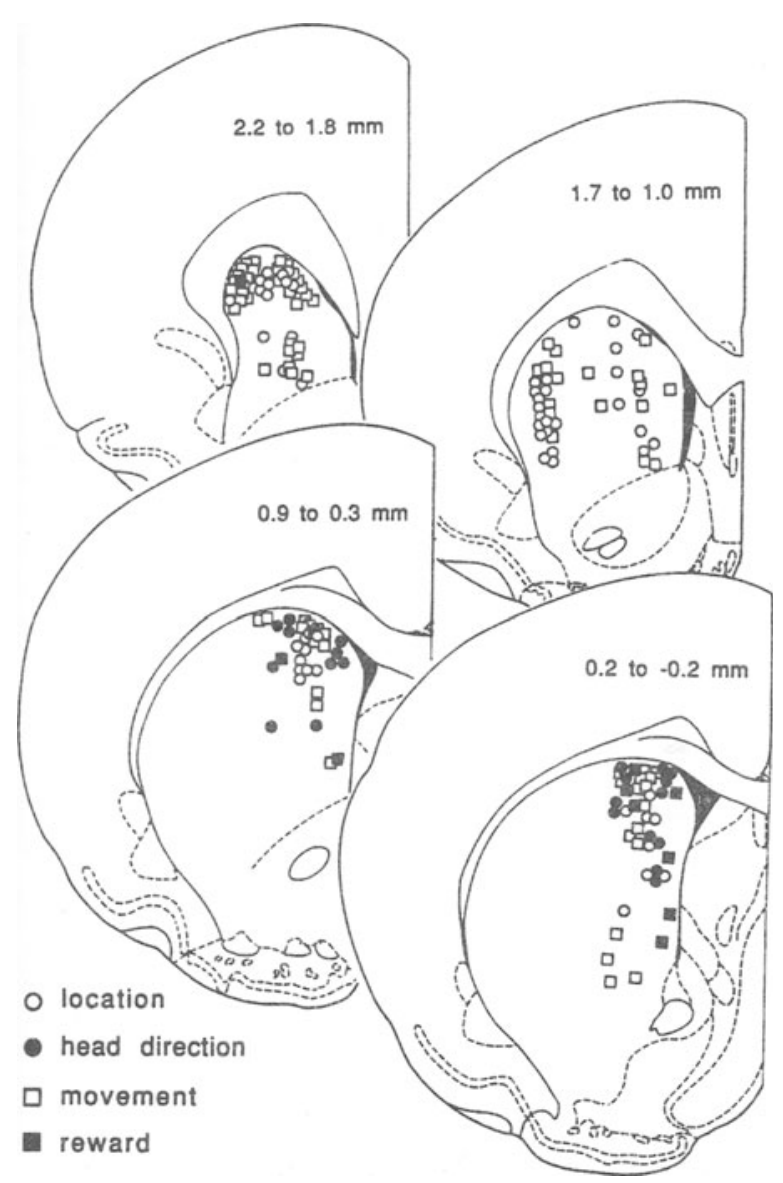

Figure 1. Schematic illustration of recording sites within the dorsal striatum (adapted, with permission, from Paxinos \& Watson, 1986; copyright Academic Press). For comparison, this figure includes not only the location and head direction cell recording sites, but also the sites where reward- and movement-sensitive neurons were found. Each symbol may represent more than a single cell since, across animals, many cells could have been recorded from essentially the same anatomical location. It can be seen that location cells were found uniformly within dorsal striatum. (The lack of symbols in the lateral-caudal region reflects the fact that that region was not sampled.) In contrast, head direction cells were preferentially identified in the dorso-medial sector of the caudal portion of the dorsal striatum. focused on only the location and head direction cell properties of dorsal striatal neurons. Location cells were recorded throughout the rostral-caudal and dorsal-ventral extents of the sampled area. Head direction cells, in contrast, were found only in the dorso-medial sector of the caudal portion of the dorsal striatum, the same area where Wiener (1993) recorded three head direction cells.

Of the 187 behaviorally correlated neurons, $68(36.4 \%)$ met our criterion for location cells, and 27 (14.4\%) were classified as head direction cells. The recorded spike amplitudes (measured as the voltage difference between the first negative and positive peaks) exhibited at least a 3:1 signal-to-noise ratio, with a mean $( \pm S E)$ amplitude of $108.1 \mu \mathrm{V} \pm 4.11 \mu \mathrm{V}$ and $92.4 \mu \mathrm{V} \pm 10.00 \mu \mathrm{V}$, respectively, for location and head direction cells. Spike duration for head direction cells $(237.4 \mu \mathrm{sec} \pm 22.64 \mu \mathrm{sec}$, measured as the time difference between the first peak and subsequent trough of the analog signal), was shorter than that of location cells ( $308.7 \mu \mathrm{sec} \pm 8.86 \mu \mathrm{sec})$, indicating that these correlates are derived from different types of cells. Spike width information by itself, however, cannot predict the behavioral correlate since movementand reward-related neurons recorded from the same animals showed spike widths that ranged from about 240 to $350 \mu \mathrm{sec}$.

\section{Location Correlates of Dorsal Striatal Neurons}

The following analyses were conducted on data acquired from well-trained rats. Consequently, as was evident by on-line video monitoring of behavior, animals did not pause midtrial to groom or to sniff. Rather, locationrelated discharge occurred as animals actively moved forward through a particular region of the maze.

Consistent with criteria used in past studies of limbic system place cells (e.g., Mizumori et al., 1992), dorsal striate cells were categorized as location cells if they had spatial specificity scores of at least 1.7 , and a reliability score of at least .25 when rats performed standard maze trials. The average spatial specificity score was $3.38 \pm$ 0.34 , and the average reliability score was $.36 \pm .03$. For comparison, hippocampal CAl place fields show on average specificity scores of about 5.0 and reliability scores of about .40 to .80 (McNaughton, Barnes, \& O'Keefe, 1983; Mizumori et al., 1996). Hippocampal interneurons, which have been argued to display significant location biases (Kubie, Muller, \& Bostock, 1990), exhibit specificity scores of 1.0 to 1.2 (Barnes et al., 1990). Information content scores were not used to identify location cells because it was not clear a priori what criterion to employ. Past studies using this measure preselected hippocampal cells that had broad fields (e.g., Knierim et al., 1995) or characterized parasubicular place fields that were inherently large (Taube, 1995b). Rather, information content scores were used to characterize location fields post hoc.

Upon visual inspection of the absolute locations on the maze in which location fields were found (see examples in Figure 2), it was clear that a subpopulation of this cell type $(n=16)$ had fields on a significant portion 

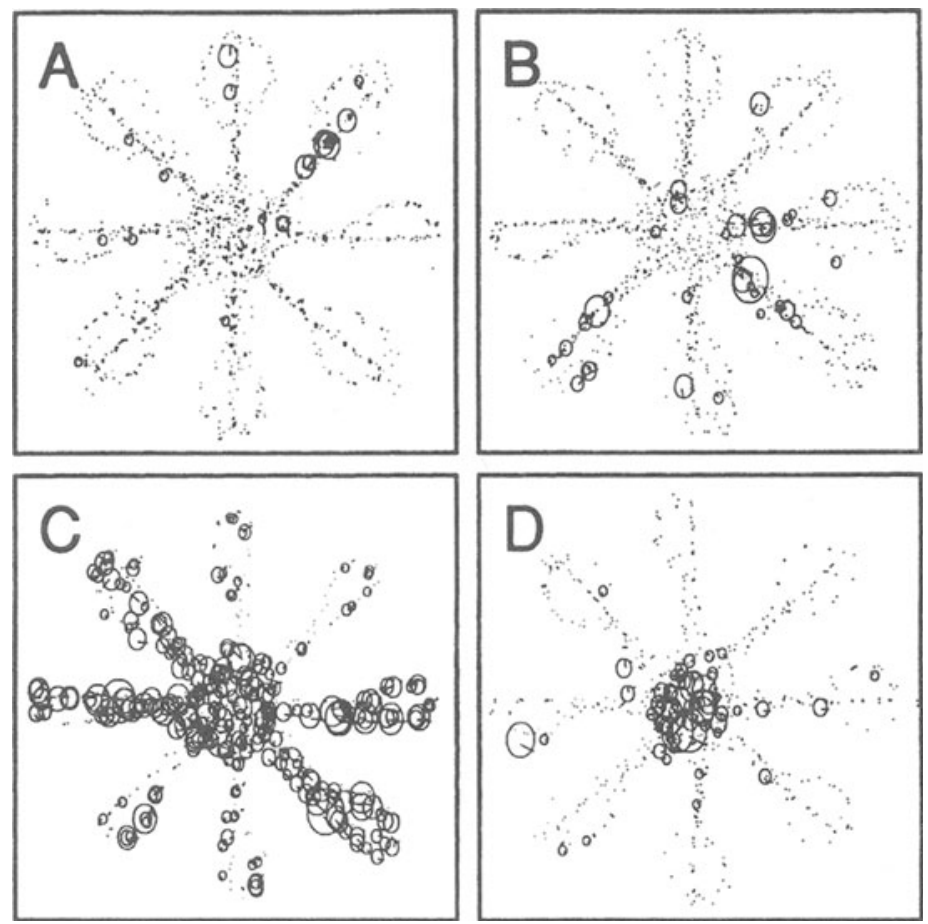

Figure 2. Examples of the spatial distribution of dorsal striatal location cell firing during performance of eight trials on a radial arm maze. Dots indicate positions occupied by the rat, while size of the circles corresponds to the local firing rate of the cell. All circles are normalized to the maximum firing rate (shown by the largest circle). Individual circles represent single traversals of a particular location when cells fired at least $20 \%$ of the maximum firing rate. To represent the extent to which location-specific firing was reliable, multiple occurrences of firing associated with the same location are represented by circles that are offset from each other. Thus, overlapping circles indicate that the cell fired upon repeated entries into the location field. Observation of overlapping circles provides an index of the reliability with which elevated firing was associated with a particular location of the animal. Vectors radiating from the center of the circles indicate the direction of diode movement while the rat occupied a particular location. Figure $2 \mathrm{~A}$ shows a highly localized and directional (outbound) field to the northeast arm of the maze. This resembles the kind of location specificity one might expect of a hippocampal place field (see, e.g., Mizumori et al., 1989). Figure 2B illustrates a more broad, yet directional, location field (spanning the east and southeast arms) with a secondary field on the southwest maze arm. The cell shown in Figure $2 \mathrm{C}$ is unusual in that it fired as the rat moved in both inward and outward directions on the east, southeast, west, and northwest arms of the maze. Finally, the center platform field shown in Figure 2D exemplifies another subgroup of dorsal striatal location cells.

of the central platform of the maze. Therefore, the analysis described below was initially carried out by comparing location field properties of cells with fields on maze arms with those cells whose fields were on the maze center. There were no differences between these subpopulations. Also, cells with place fields that were expressed as an animal moved in only one direction on a maze arm (directional arm field, $n=32$ ) were compared with cells with nondirectional location fields on maze arms $(n=$ 20 ), and again no differences were found in terms of the location field properties (except, of course, for the directional bias).
Maguire et al. (1998) recently postulated that the caudate region of humans determines the velocity of movement through an environment. Therefore, we examined the relationship between location-specific firing and velocity of movement irrespective of direction. Velocity was determined using the $256 \times 256$ spatial coordinate system with 100-msec temporal resolution. A Pearson's correlational analysis revealed no significant correlation between velocity and firing rate of (arm) location cells $(r=.15)$.

The following manipulations of the sensory environment were performed. The order of test was mixed to 
counterbalance the effects of experience on location cell responses (Knierim et al., 1995).

Effects of darkness. An important feature about hippocampal place cells is that they are sensitive to changes in the visual context (see, e.g., Barnes, Suster, Shen, \& McNaughton, 1997; Markus et al., 1994; Mizumori, Ragozzino, Cooper, \& Leutgeb, 1999; Mizumori \& Williams, 1992; Tanila, Shapiro, Gallagher, \& Eichenbaum, 1997). That is, place field characteristics change when there are significant changes in the visual environment. For example, Markus et al. (1994) found that hippocampal place cells of well-trained animals became less reliable and less specific when sudden darkness was imposed during radial maze trials. We have also found this to be true for hippocampal neurons recorded in our test situation (Mizumori, Ragozzino, et al., 1999). To facilitate comparison with such hippocampal studies, we tested a subset of dorsal striatal location cells $(n=18)$ according to a lightdark-light test procedure in which animals $(n=8)$ first performed five trials under standard light conditions (Trials 1-5), then five trials with the lights turned off (Trials 6-10), followed by five trials in which the lights were restored (Trials 11-15). Room lights were turned off and on by a remote switch during the intertrial interval as the rat was restricted to the central platform of the maze. Lights remained off during the intertrial intervals between Trials $6-10$.

The following behavioral analysis included recording sessions of both location and head direction cells to permit statistical comparisons across successive phases of the test. Rats made more errors when tested in darkness: $0.39 \pm 0.12,0.82 \pm 0.16$, and $0.50 \pm 0.15$ errors were made during the light, dark, and recovery phases, respectively. The difference in errors made across these test phases was verified statistically $[F(2,29)=3.51, p<.05]$. Although animals spent more time performing trials in darkness than in the initial light condition, the latency to complete a trial did not return to that of the initial light trials during the subsequent recovery phase (139.0 \pm 7.1 , $151.3 \pm 9.3$, and $157.4 \pm 20.8 \mathrm{sec}$ during light, dark, and recovery phases, respectively; $p>.10$ ). The time required per arm choice did not differ across dark and light test phases.

Figure 3 exemplifies the variety of light-dark-light effects that were observed. Cell 54007.4 (top row, Figure 3) showed reduced overall fïring from $0.52 \mathrm{~Hz}$ during light trials $(1-5)$ to $0.22 \mathrm{~Hz}$ during dark trials $(6-10)$. The firing rate returned to $87 \%$ of the original rate by Trials 11-15. During the three phases of testing, the location field shifted from outward on the south maze arm (with $100 \%$ reliability), to outward on the southwest arm (with $60 \%$ reliability), and then back to outward on the south maze arm (with $100 \%$ reliability). A similar drop in firing rate with clear changes in location of the field was shown by one other cell. Another effect of darkness was shown by three cells, and is illustrated in the second row of Figure 3. It involved a change in the location of the location field firing while maintaining the same mean rate. Cell 32517.1 reliably fired when the rat approached the ends of the E, SE, S, SW, and $W$ arms of the maze during Trials 1-5. During Dark Trials 6-10, the cell exhibited a major location field on the NE arm, and minor fields on the $\mathrm{N}$ and $\mathrm{E}$ arms. During the restored light conditions (Trials 11-15), the same cell no longer fired on the NE arm; rather, the pattern resembled more that observed during Trials $1-5$. The third row of Figure 3 illustrates another pattern of dark effects shown by four cells: the apparent broadening of the original location fields. Cell 48633.1 had a location field that became less spatially distinct during dark trials, only to resume its normal field during Trials 11-15. The fourth row of Figure 3 illustrates a location field of one cell (cell 46208.1) that became more spatially distinct in darkness. Five other location cells showed both reduced spatial distinction and a lower mean firing rate when tested in darkness (see cell 47010.3 of Figure 6 for an example). Only 3 of the 18 cells tested did not show a change in rate or spatial distinction during dark trials.

A trial-by-trial analysis revealed that the disruptions shown in Figure 3 were usually evident within the first dark trial (Trial 6). Upon restoring the room lights, it was often (but not always) the case that the baseline pattern of firing was observed on Trial 11, the first trial in which the lights were restored. In cases where the fields were not completely restored by the end of the recording session, the baseline location field was fully restored by the next day's session. This delayed restoration suggests that as with hippocampal place cells (see, e.g., Sharp, Blair, Etkin, \& Tzanetos, 1995; Wiener, Korshunov, Garcia, \& Berthoz, 1995), at least a portion of the location cells may be sensitive to more than just the visual environment.

Five of the dorsal striatum location cells (from 4 rats) were also tested by first carrying the rat into the maze room in total darkness, then requiring the rat to perform five maze trials (dark-light test). Between Trials 5 and 6 , the room lights were turned on by a remote switch (out of view of the rat) while the rat remained on the center platform of the maze. The rat then performed five additional trials under standard illuminated training conditions. Importantly, the specific behavioral responses required of the animal were the same during performance in dark and light conditions. Relative to Trials $6-10$, the four armselective location cells (recorded from different animals) showed less spatial selectivity when the rat performed the first five trials in darkness. A fifth cell showed the same center-selective firing in dark and light conditions. These data appear to be consistent with the results of the light-dark-light test, suggesting that striatal location cells are sensitive to changes in the visual environment despite the constancy of the behavioral demands.

Behavioral analyses showed that during dark-light tests, rats made slightly more errors when tested in darkness. Although the difference was small $(1.07 \pm 0.21$ errors during darkness and $0.32 \pm 0.10$ errors in the light condition), the difference was statistically significant $[F(1,14)$ $=14.46, p<.01]$. Moreover, animals spent more time 

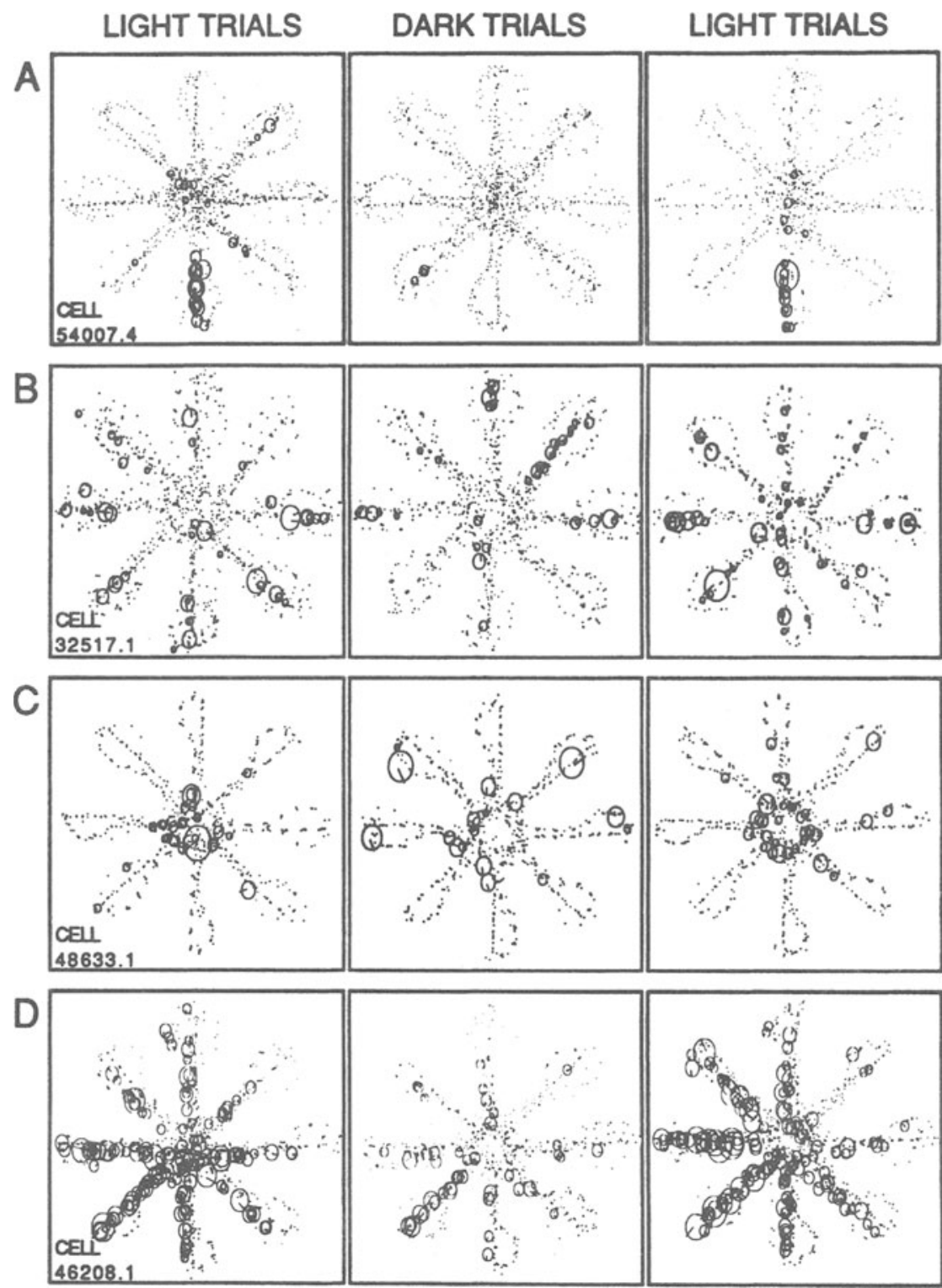

Figure 3. Four examples of dorsal striatal location field responses when animals were subjected to the light-dark-light test. Animals first performed five maze trials in standard light conditions. During Trials 6-10, the lights were turned off, followed by restoration of light during Trials 11-15. Figure $3 \mathrm{~A}$ shows a striatal location field that was directional as well as location specific for movement in the outward direction on the south maze arm. The firing rate of the cell was dramatically reduced during dark trials, and the location field seemed to have shifted clockwise by $45^{\circ}$. Figure $3 B$ shows a cell that becomes differentially selective during dark trials. Figure $3 \mathrm{C}$ shows a field that becomes more dispersed during dark trials relative to light trials. In Figure $3 D$ it can be seen that a location cell becomes more selective during dark trials. These data, together with those presented in Figures 6 and 7, indicate that visual information impacts the specificity of dorsal striatal location cells.

performing trials in darkness than in the light condition $[159.7 \pm 10.3 \mathrm{sec}$ in darkness and $135.5 \pm 9.8 \mathrm{sec}$ in light; $F(1,14)=8.22, p<.02]$. The increased time spent performing dark trials was likely due to the fact that more errors were made since the time spent per choice did not differ across dark and light test phases.
Effects of novel environments. The effects of exposure to a novel environment on location field activity were tested for two cells (recorded from 2 rats). Animals first performed five trials in the familiar room to verify location-specific firing. This was followed by at least five trials in a second recording room that had a different ra- 
A

- LIGHT TRIALS: FAMILIAR ENVIRONMENT

… DARK TRIALS: NOVEL ENVIRONMENT

- - LIGHT TRIALS: NOVEL ENVIRONMENT
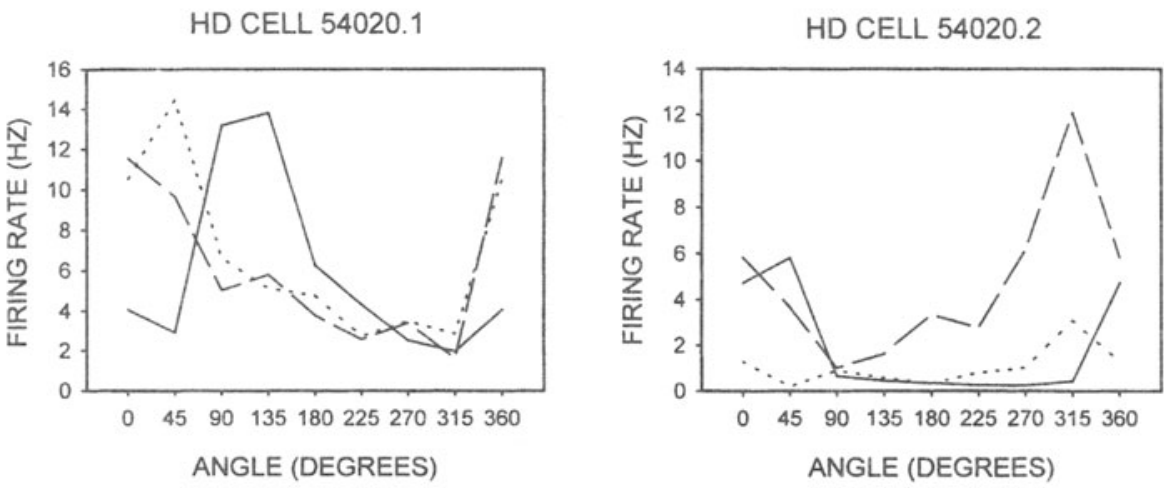

\section{LIGHT TRIALS: FAMILIAR ENVIRONMENT}

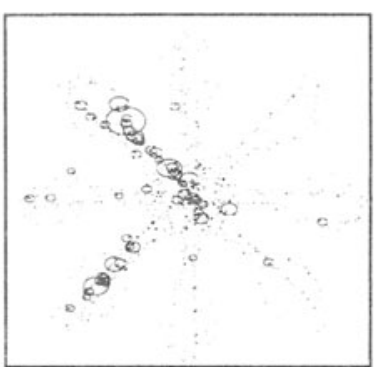

NOF

DARK TRIALS:

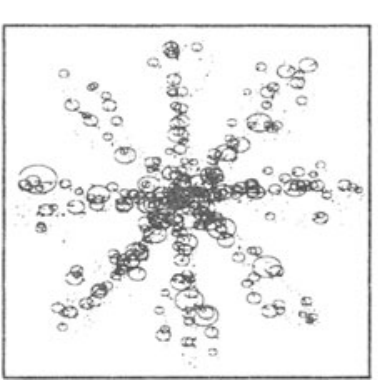

LIGHT TRIALS: NOVEL ENVIRONMENT

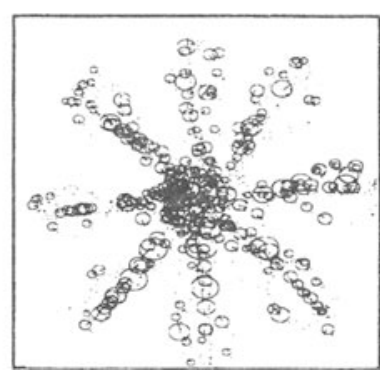

Figure 4. The responses of two striatal head direction cells $(A)$ recorded simultaneously with one striatal location cell (B) when the rat was introduced into a novel environment. Baseline trials were first performed in a familiar environment. The rat entered the novel room in darkness, and the lights remained off as the rat performed the first five trials. Then, the room lights were turned on, and the rat performed five light trials. Relative to the baseline period, when the rat performed light trials in a familiar environment, the two head direction cells changed their directional firing properties during dark trials performed in the novel room. Cell 54020.1 seemed to shift its absolute directional preference by $45^{\circ}-90^{\circ}$, nevertheless maintaining clear head direction firing $\left(0^{\circ}\right.$ corresponds to west, $45^{\circ}$ to southwest, and so on). Cell 54020.2, on the other hand, lost its head direction characteristic during dark trials. When the room lights were turned on in the novel room, Cell $\mathbf{5 4 0 2 0 . 1}$ shifted its directional preference by another $45^{\circ}$, where it remained during subsequent test days in the novel room. Cell 54020.2 suddenly exhibited clear head directional firing when the lights were restored. It is interesting to note that in the familiar room, the directional preferences of the two head direction cells were about $90^{\circ}$ apart, and that during the light trials in the novel room, the directional preferences of the two cells were again about $90^{\circ}$ apart. In contrast to the responses of the head direction cells, the location cell no longer exhibited location-specific firing when the rat performed in the novel room with the lights on or off.

dial maze surrounded by novel cues. Neither cell showed localized firing in the new environment (see Figure 4 for one example). This was the case regardless of whether the rat performed five dark trials (in the novel room) before five light trials in the new environment, or whether the rat performed the first five trials with the lights on.

Effects of reward magnitude shifts. Given the numerous reports of reward-sensitive neurons in primate striatum (see introduction), it was of interest to investigate the influence of reward value on striatal location fields. For those rats trained on the differential reward procedure, we tested location field stability following reversal of the expected reward magnitude. That is, maze arms that previously contained large rewards were now baited with a small reward for Trials $6-10$, and vice versa for arms that previously contained small rewards. Only 2 out of 23 location cells tested clearly showed changed specificity during trials in which the reward values were reversed. This suggests that, as was found for ventral striatum (Lavoie \& Mizumori, 1994), most striatal loca- 
tion cells are unaffected by changes in reward. However, a small subset of dorsal striatal cells may represent integrated reward and spatial information.

\section{Head Direction Correlates of Dorsal Striatal Neurons}

Confirming the initial description of three head direction cells by Wiener (1993), we found head direction cells ( 27 cells recorded from 13 rats) in the medial dorsal striatal region. These cells showed dramatically increased firing when an animal's head was oriented along a particular direction in space irrespective of the animal's location on the maze. To confirm this classification, animals tested with single-diode tracking were subjected to a passive movement test to verify that the directional preference of the cell was independent of the location of the animal. In this evaluation, the animal was hand-held by the experimenter, then moved to random locations in the maze room. At these different locations, the rat was pointed in different directions to identify the preferred direction of the cell being recorded. In all cases, the directional preference was constant relative to an absolute direction in space irrespective of the local visual cues or location of the rat. For rats recorded with double-diode tracking, tuning curves for directional firing further demonstrated very clearly the head direction nature of these cells (see Figures 6, 7, 9, and 10 for examples). There was no significant correlation between velocity of movement per se and the firing rates of head direction cells $(r=.12)$.

As has been reported for head direction cells recorded from other brain areas (e.g., LDN: Mizumori \& Williams, 1993 ), dorsal striatum head direction cells had an average directional index of $6.68 \pm 0.84$. The mean firing rate as the rat faced the preferred direction of the cells was $28.76 \pm 4.79$, while the mean rate as the rat faced the directly opposite nonpreferred direction was $4.26 \pm$ 1.63. There was a significant negative correlation between directional index and overall mean firing rates of cells $(r=-.52, p<.02)$, indicating that, not unexpectedly, the more broadly tuned head direction cells discharged more often during maze trials. A subpopulation $(n=11)$ of dorsal striatum cells showed a relatively broad directional preference that spanned two adjacent directions (arms) on the maze (e.g., N and NE, or S and SW). The directional index of cells showing the single-arm directional bias was 8.60 , while the directional index of cells showing two-adjacent-arm directional biases was 4.76. These scores were significantly different $[F(1,26)=$ $6.59, p<.02]$.

Effects of darkness. To facilitate comparisons with dorsal striatum location cells, 22 of the dorsal striatum head direction cells (recorded from 12 rats) were examined under the light-dark-light test and dark-light test conditions described above for location cells. The mean rate as the animal moved outward in each of the eight directions offered by the maze arms during standard maze trials was used to determine the baseline directional preference and tuning curves of the cell. (For cells recorded with the single-diode tracking system, inbound rates were not entered into the calculation because of the potential contamination by turning behavior of the animal.) All eight rates were normalized relative to the firing rate observed in the preferred direction during baseline trials (i.e., the first light trial phase of each test) in such a way that the normalized rate in the preferred direction was 1.0. Figure 5 presents these rates for each of the eight directions, with $0^{\circ}$ coinciding with the baseline preferred direction. A repeated measures ANOVA revealed that during the light-dark-light test, there was a significant repeated measures effect. That is, there was preferential firing at orientation $0^{\circ}$ relative to orientations in other directions $[F(7,42)=75.70, p<.001]$, with no effect of test condition $[F(2,42)=0.24, p>.70]$, and no interaction $[F(2,42)$ $=1.05, p>.40]$. Although the dark test did not produce statistically significant changes in directional preferences across the entire population of head direction cells tested, it should be noted that five head direction cells did show clear and consistent changes in preferential firing by about $45^{\circ}$. The directional preference of these cells was shifted, and remained so throughout the dark trials. Most of the remaining 22 cells tested showed a shift by $45^{\circ}$ but during only one of (what was typically) five dark trials. Following this shift was a return to the original preferred direction even though the rat was performing in darkness. Figure 6 provides an example of simultaneously recorded dorsal striatal head direction and location cells during the dark manipulation. Each spatial plot reflects the summed activity over five trials. Tuning curves from individual head direction cells illustrate the lack of an effect of imposed darkness that was often observed (Figure 6).

Thus, while the summed data across all dark trials suggest no statistically significant effect of dark trials, individual trial-by-trial analysis show that a subset of cells responded at least initially to the dark test. This was true for cells recorded individually ( $3 / 14$ cells), as well as simultaneously with other head direction cells ( $2 / 8$ cells). On one occasion, three head direction cells were recorded simultaneously: Cells 43518.1 and 43518.2 showed no consequence of turning off the lights while Cell 43518.3 showed an initial shift by $45^{\circ}$ during the first dark trial, followed by a restoration of the original directional bias by the second dark trial. The original directional preference continued to be observed on subsequent dark trials. On another occasion, two head direction cells were recorded simultaneously: Cell 46224.3 changed by $45^{\circ}$ its directional preference during the first dark trial, followed by a return to its original directional preference by Dark Trial 2. Cell 46224.4 showed an unusual pattern of maintaining its original directional preference during the first dark trial, followed by a $45^{\circ}$ shift to the right that persisted during subsequent dark trials. In a 3rd animal, we recorded another trio of head direction cells during the light-dark--light test. All three of these cells showed no evidence of change during the dark phase of testing.

A second test of the influence of visual input to head direction firing was to expose rats to the dark-light test, 

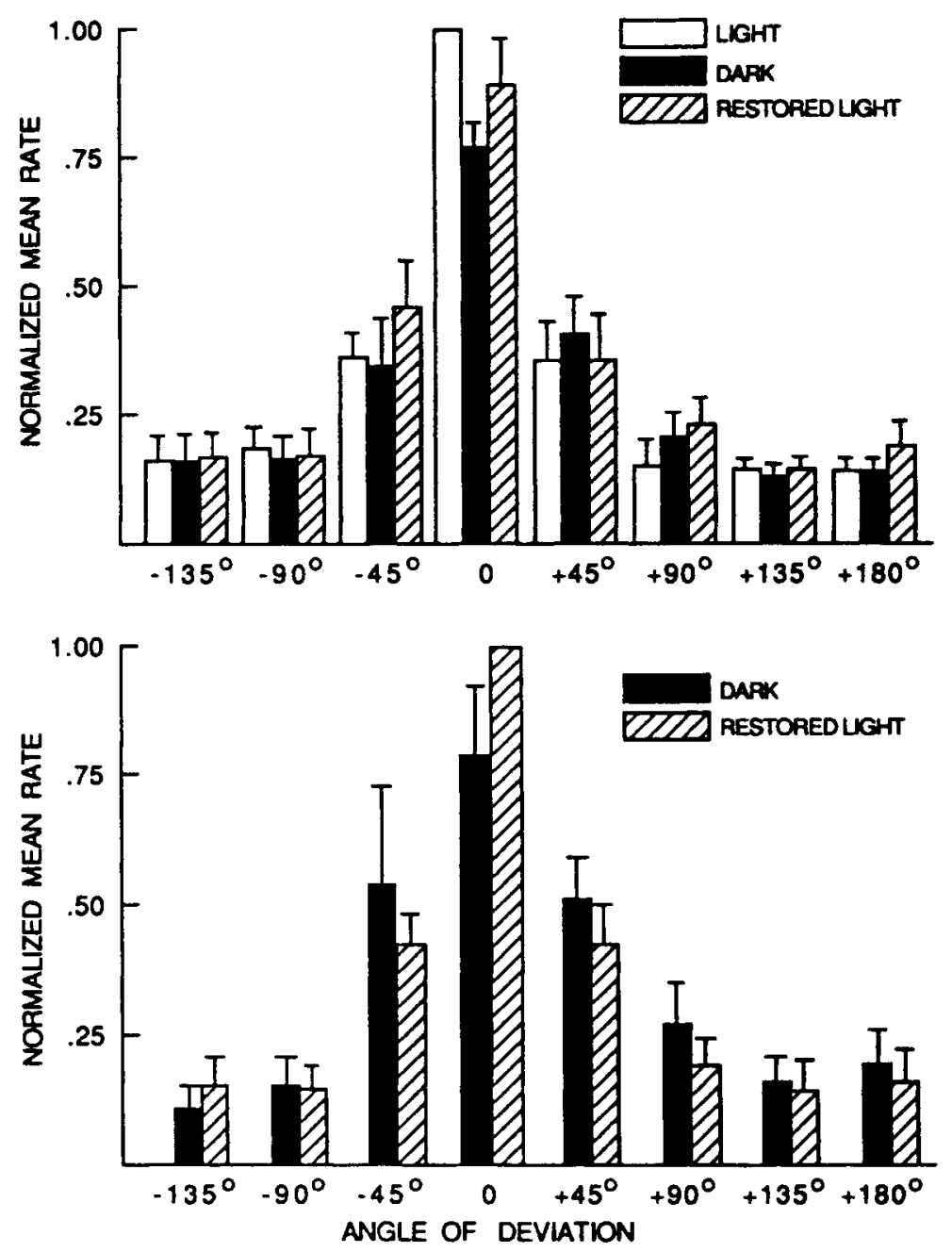

Figure 5. Histograms presenting the group mean $( \pm S E)$ of normalized firing rates (see text for a description of the normalization procedure) relative to heading direction during performance on the radial maze. The preferred direction of a cell was designated the " 0 " angle of deviation. Mean firing is illustrated in $45^{\circ}$ increments to the right $(+)$ or left $(-)$ of the preferred direction. Top panel: During the light phase of the light-dark-light test, head direction cells showed a directional preference that is similar to that observed in other structures, such as the lateral dorsal thalamus (Mizumori \& Williams, 1993). A group statistical analysis indicated no significant shift in head direction firing when lights were subsequently turned off (dark phase). However, as has been indicated in the text, a subset of head direction cells did show subtle shifts in directional preferences during dark trials. Bottom panel: A similar pattern emerged during dark-light tests: Group summary statistical analyses showed no significant effect of initial dark trials. However, subgroups of individual cells showed reliable, albeit subtle, shifts in directional preferences.

in which an animal was carried into a dark test room, where it performed five maze trials in darkness before performing five more trials with the lights on. As in the analysis of the light-dark-light test, the firing rate of a cell as the animal moved in each of the eight directions on the maze was normalized against the mean firing rate in the preferred direction during the light phase of the dark-light test. Figure 5 (bottom) presents a population summary of the 13 cells recorded from 9 rats. A repeated measures ANOVA suggests that there was no effect of darkness $[F(1,24)=0.12, p>.70]$, and that significant directional selectivity was observed $[F(7,24)=23.92$, $p<.001]$. There was no interaction $[F(7,24)=1.11, p>$ .36]. Inspections of individual cell data revealed that while 8 cells showed the same preferred direction during dark trials, as was subsequently observed in light conditions, the directional biases of 5 cells were noticeably different between dark and light trials. The preferred direc- 

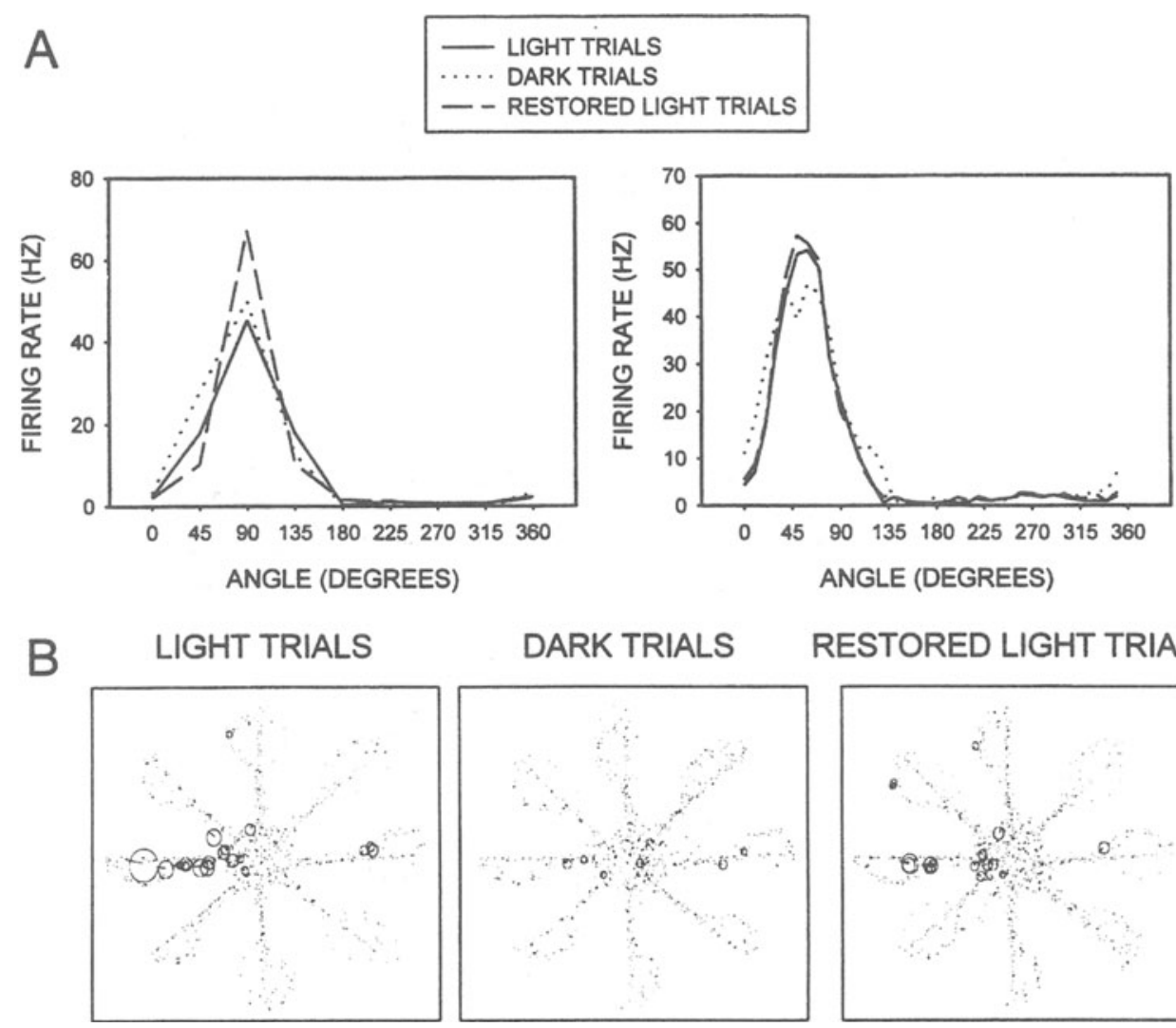

RESTORED LIGHT TRIALS

Figure 6. Responses of dorsal striatal head direction cells (A) and a location cell (B) during light-darklight tests. In (A), directional tuning curves are presented for two different cells. The head direction cell shown on the left was recorded simultaneously with the location cell shown in B. Its directional preference to the south was maintained during all phases of the test. Similarly, the second head direction cell (shown to the right in A) maintained the same directional preference during all phases of the test. Occasionally, the peak rate was observed to be lower during dark trials. Note that even though the directional tuning curves were generated from single-diode (A-left) and double-diode (A-right) data, the consequences of the experimental manipulation are shown to be the same. Due to the higher spatial resolution of double-diode recording, however, the tuning functions for double-diode data tend to be more narrow than those for singlediode data. In contrast to head direction cells, most of the striatal location cells showed dramatic changes in their spatial correlate during dark trials. In the example provided in B, the location cell preferentially fired when the rat moved west on the maze during standard light trials. During subsequent dark trials, this cell rarely fired. The original location field was restored during performance of additional light trials.

tion during dark trials was frequently found to be about $45^{\circ}$ to $90^{\circ}$ clockwise or counterclockwise relative to the baseline preferred direction (see Figure 4 for an example). On two occasions, a pair of head direction cells was recorded simultaneously. For one pair, both cells showed the same directional preference during dark and light phases of the test. For another pair, one head direction cell showed a modest $\left(45^{\circ}\right)$ shift in directional preference in darkness, while the second cell showed no shift. In all cases, the original preferred direction was reestablished by the first trial after the lights were restored (Trial 11 ).

Despite the individual cell variations in response to the dark-light test, the overall pattern of effects complements that observed for the light-dark-light test described above. Both test results suggest that striatal head direction cells incorporate visual information to some extent to deter- mine the precise directional preferences of cells. Nonvisual information must also significantly contribute to the direction code since general head direction discharge is observed before animals are exposed to the visual environment (as shown during the dark-light test).

Effects of cue rotation. Since the head direction correlates did not show dramatic changes during dark testing, the extent to which these head direction correlates incorporate information about the available distal visual cues becomes an issue. Therefore, we tested the response of three head direction cells to a $180^{\circ}$ rotation of the distal cues. For two cells, the rats first performed five standard maze trials, followed by five maze trials with the lights on and the cues rotated. The rat was placed in a holding cage just outside of the maze room while the cues were rotated. The directional preference of the head 

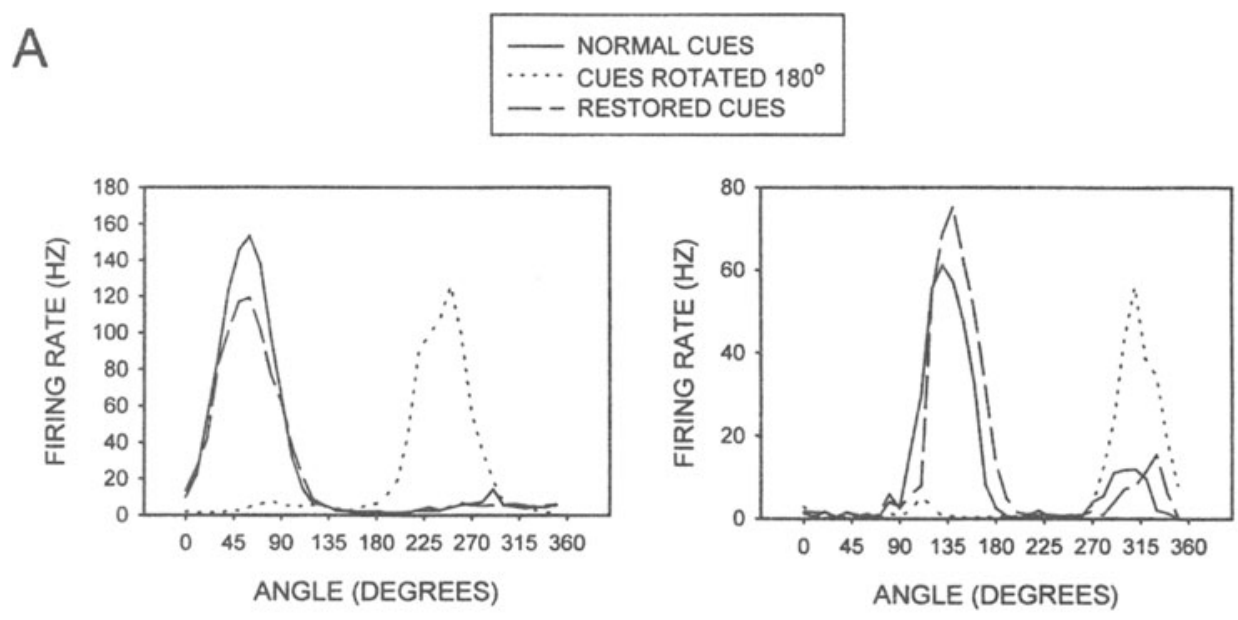

NORMAL CUES

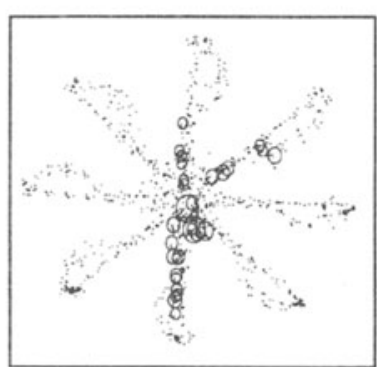

CUES ROTATED $180^{\circ}$

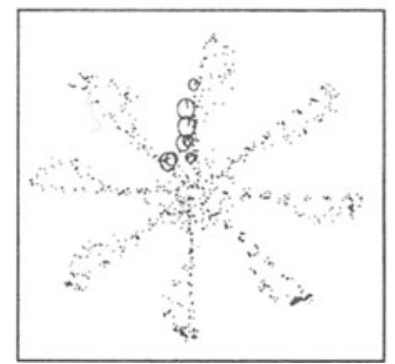

\section{RESTORED CUES}

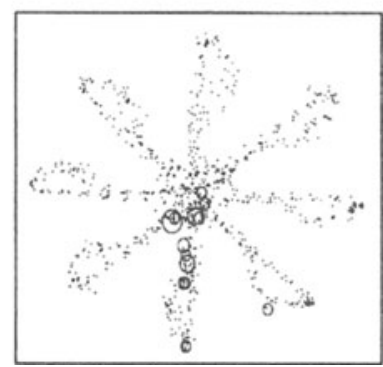

Figure 7. Reliance on distal visual cues during standard light trials is shown for two striatal head direction cells in $A$ and a striatal location cell in B. Both head direction cells were recorded with the double-diode tracking system. It is clear that the directional preferences of these cells rotated by an amount that was comparable to the degree of cue rotation. Similarly, the location field can be seen to rotate by $180^{\circ}$ from the south maze arm to the north maze arm following cue rotation. When the cues were restored to their original locations, the location fields were observed to also return to the south arm.

direction cells rotated with the cues (e.g., Figure 7A). Recorded simultaneously with this head direction cell was a dorsal striatal location cell. The location field also rotated with the cues (Figure $7 \mathrm{~B}$ ). For the third head direction cell tested, the rat was carried into the test room in darkness with the distal visual cues rotated $180^{\circ}$ from their original position. The rat first performed Trials $1-5$ in darkness. The lights were then turned on while the rat remained on the central platform. Trials $6-10$ were performed with the lights on and cues rotated with respect to other stationary room cues (e.g., the maze, auditory cues, etc.). Between Trials 10-11, the rat was placed in a holding cage just outside the testing room while the cues were rotated back to their original location. The rat was then brought back into the lighted room, where it performed Trials 11-15. As was the case for the cells shown in Figure 4, the initial dark period resulted in a shift of the original directional preference of the cell. When the lights were turned on, the directional preference became aligned to the rotated cues. When the cues were restored to their original locations, the directional prefer- ence of the cell shifted accordingly. Together, these data indicate that when visual cues are available, the head direction cells utilize current visual information to establish a directional preference.

Effects of maze rotation. When access to visual cues is unavailable (e.g., during the dark trial phases of the light-dark-light and dark-light tests), input from nonvisual systems may exert significant control over head direction firing. This hypothesis was tested by the following experiment in which rats performed 5 maze trials under standard light conditions (Trials $1-5$ ) followed by five trials in darkness (Trials 6-10). Just prior to Trial 6, while the rat remained on the central platform in darkness, the maze and rat were rotated together by $45^{\circ}$ or $90^{\circ}$ relative to the original position. As a control procedure, the same head direction cells were also tested following maze/rat rotations, when the lights remained on for all 10 trials. It is worth noting that the slow rotation was accomplished by manual rotation of the maze at speeds that were likely above the threshold for detection by the rat's vestibular system. Four head direction cells (recorded 
A

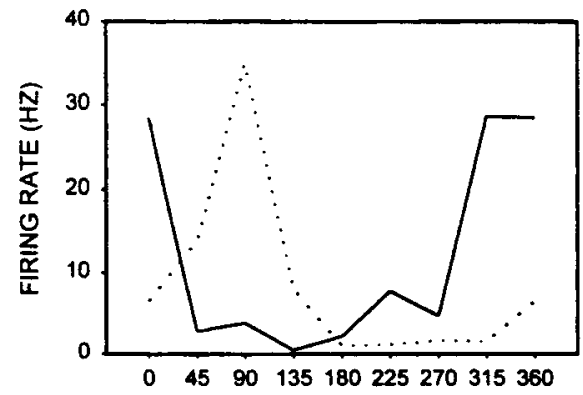

B

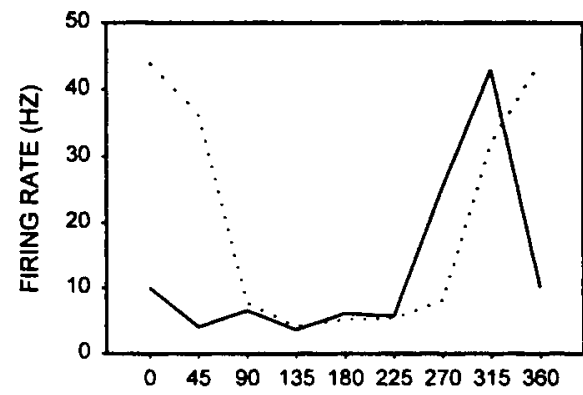

Q
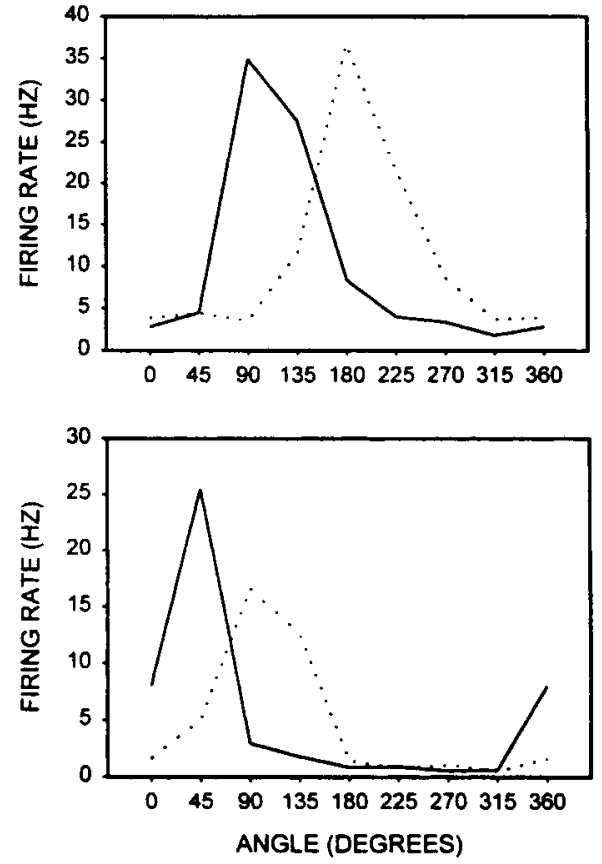

$45^{\circ}$ MAZE

ROTATION

$90^{\circ}$ MAZE

ROTATION

45 MAZE

ROTATION

$45^{\circ}$ MAZE

ROTATION

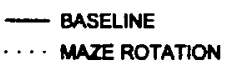

Figure 8. Directional tuning curves from four different striatal head direction cells before and after rotation of the maze by the amount indicated for each panel. The cell shown in A rotated by about $90^{\circ}$ following maze rotation of $45^{\circ}$, whereas the cell in $B$ rotated by about $45^{\circ}$ following maze rotation of $90^{\circ}$. The two cells shown in $C$ were recorded simultaneously. These cells showed different responses to the single maze rotation, suggesting that changes in the environment do not always produce predictable and systematic changes in head direction preferences.

from 3 rats) were tested in both dark and light maze/rat rotation conditions. Figure 8 indicates that all four cells showed a shift in directional preference when the maze was rotated in darkness. Interestingly, the degree of rotational shift in directional preference was not predicted by the degree of maze rotation in three of the four cells.
In fact, when two head direction cells were recorded simultaneously, the preference of each cell appears to have changed by a different amount. In contrast, none of the cells changed directional preferences when the maze/rat was rotated in light conditions. These data suggest that when visual cues are available, they have an overriding 
influence in determining the directional preference of head direction cells. However, when such cues are not available, the original directional preference is maintained by nonvisual (i.e., idiothetic and intramaze) cues.

Effects of passive movement. The maze rotation experiment results (described above) indicate that during dark, but not light, trials, the head direction cells are sensitive to intramaze and/or idiothetic information. In an attempt to distinguish these possibilities, animals $(n=2)$ were first carried directly from the colony room into the familiar test room in darkness. They then performed Trials $1-5$ in darkness. Trials $6-10$ were also performed in darkness. However, during the latter set of dark trials, the experimenter picked up the rat and placed it on the end of the arm that was to be the first choice of the trial. The rat was then free to complete subsequent choices of the trial without interference from the experimenter. The arm selected as the first choice was randomly determined, and without consideration of the directional preference of the cell being recorded. If the directional firing was driven solely by intramaze cues, it should not be disturbed by this procedure. On the other hand, if the directional firing was dependent on idiothetic information, the passive movement might be expected to disrupt the underlying idiothetic computations that guide behavior. As a control, the same cells were also recorded during five standard light trials followed by five light trials during which the rat was picked up and placed on a maze arm for its first choice of a trial. The order of testing was counterbalanced across cells. Figure 9A (top) shows an example of one head direction cell's response. The other cell tested in this manner showed precisely the same pattern of effects. Briefly picking up the rat in darkness, but not in light, resulted in an attenuation of the maximum firing rate as well as an increase in the width of the directional tuning curve. These data suggest that during darkness, idiothetic rather than intramaze information contributes to directional tuning.

The results described thus far are consistent with the view that, when tested in light conditions, the striatal head
A

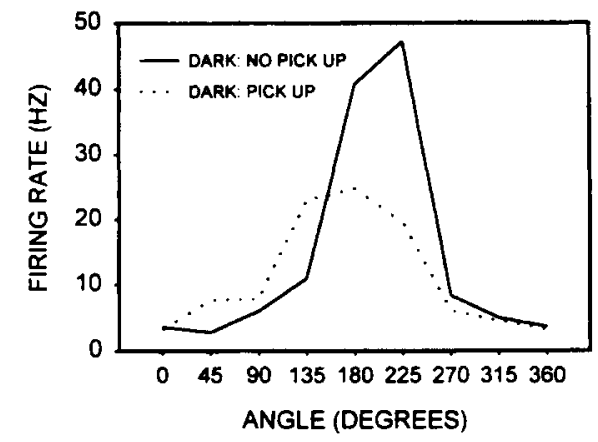

B

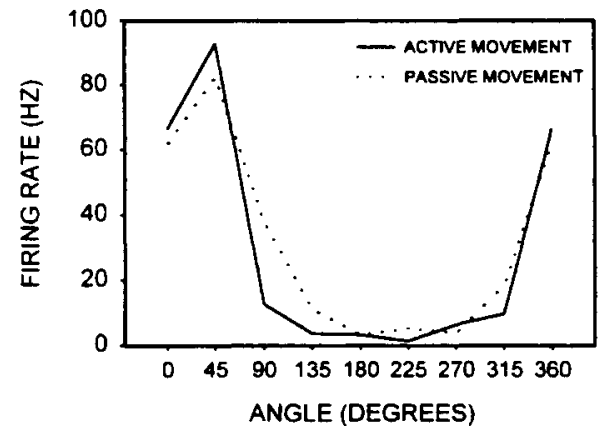

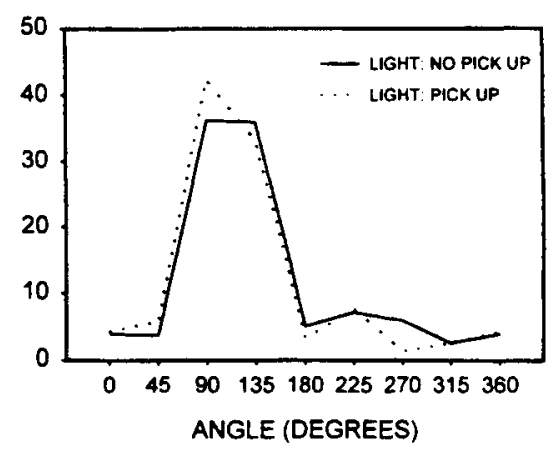

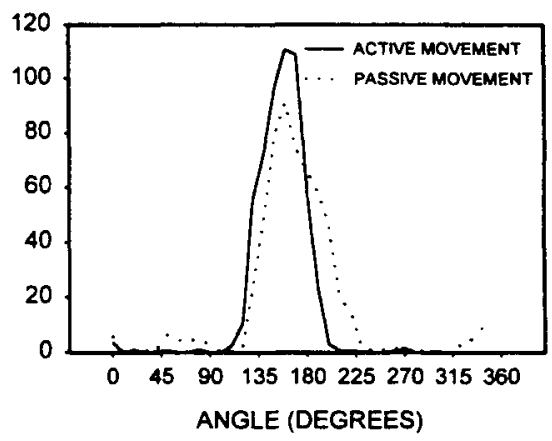

Figure 9. Responses of striatal head direction cells to two passive movement tests. The one cell shown in $\mathbf{A}$ was tested following the same manipulation performed either in darkness (left panel) or in light (right panel) conditions. During dark trials, the rat was either not picked up by the experimenter during the trial (dark: no pickup condition) or picked up and carried to its first choice of each of the dark trials (dark: pickup condition). For the latter, the rat was then allowed to complete the trial without interference from the experimenter. As a control, the same manipulation was carried out with the room lights on. It can be seen from the tuning curves that the head direction cell lost some of its head direction selectivity when idiothetic computations were disrupted in darkness. Picking up the rat with the lights on had no effect on the cell correlate. A second passive movement test involved hand carrying the rat above the maze arms with the room lights on, allowing the rat to observe visually the same cues as when it actively moves about the maze. A comparison of the passive and active movement directional tuning curves shows no clear effect of passive movement. Together these data are consistent with the view that during light conditions, the directional correlates are not importantly influenced by idiothetic cues. However, in darkness, idiothetic cues predominate. 
direction cells are guided by external visual cues. However, when visual cues are inaccessible, the directional code could be maintained by other sensory, presumably idiothetic, information. It remained an issue whether in light conditions, idiothetic and/or intramaze information significantly influenced head direction discharge. To test this, seven head direction cells (from 4 rats) were recorded as the experimenter hand-carried the rat (about 4 in. above the maze surface) inward and outward along the maze arms. A comparison was made between directional firing patterns during such passive movements and those observed during active (voluntary) movement. Three cells showed no difference in directional preference of the cell during active or passive movements (Figure 9B, left panel), while four other cells showed a modest shift of at most $45^{\circ}$ (Figure 9B, right panel). When directional indices of all cells tested were compared statistically across movement conditions, they were not found to be different. Thus, it appears that the head direction correlate is not significantly influenced by idiothetic or intramaze cues when visual cues are available.

\section{Effects of Novel Visual Environments}

Exposure to new visual cues in a familiar test room and maze. The findings of the visual and passive movement tests suggested that the striatal head direction cells use visual and idiothetic information on a conditional basis. This interpretation was further tested by varying the route by which animals were transported from the animal colony room to a familiar maze room and by varying the familiarity of the room cues. A rat was carried in a covered container to a familiar maze room via either the normal (direct) route or a novel (circuitous) route that took the rat in and out of the laboratory and down hallways outside of the laboratory. The rat then entered the maze room with the familiar set of visual cues placed within the curtained environment, or it entered the maze room after the original cues and the curtains surrounding the maze had been removed. In the latter condition, the rat was effectively placed on a familiar maze within a familiar room that contained new distal visual cues (e.g., rack, doors, and miscellaneous laboratory equipment).

Four head direction cells (from 4 rats) were tested according to the above paradigm. Three of the four cells showed the following pattern of effects (see Figure 10A for an example). Upon entering the maze room after direct route transport, the directional preferences of the head direction cells were not different from baseline (data obtained on previous days under standard training conditions) regardless of whether the maze was surrounded by familiar or novel cues. On the other hand, when the same rat was carried along a novel, circuitous route, the directional preferences changed by $180^{\circ}$ when new cues were presented in the otherwise familiar test room. Circuitous route entry into the maze room with familiar cues did not affect the baseline directional preferences. Thus, if familiar visual or idiothetic information were available, the directional preferences of the head di-
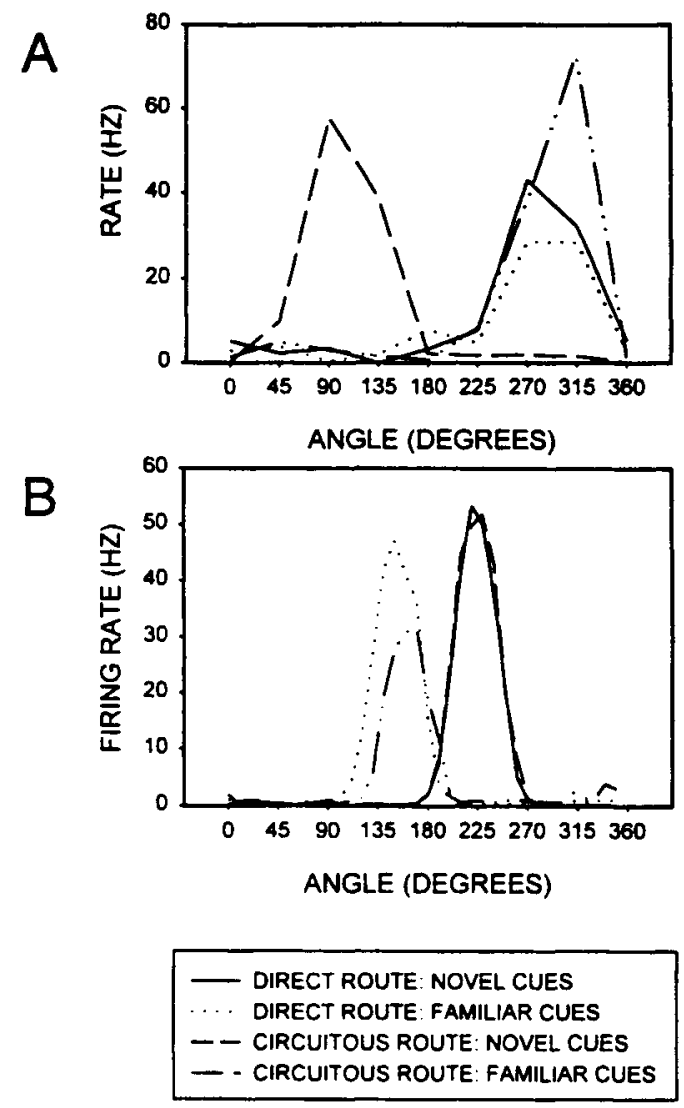

Figure 10. Another test of the relative influence of idiothetic and visual contributions to head direction firing of striatal neurons involved varying the route by which animals were carried to the maze room (from the colony room), and varying whether familiar or novel visual cues were found in the otherwise familiar room. Two patterns of responses were observed. One pattern (observed for three cells and illustrated by the cell in A) demonstrates the ability of these cells to switch between idiothetic and visual information to determine a cell's directional preference. That is, the directional preference of the cell did not change as long as one or the other type of information was familiar. The directional preference changed only when both idiothetic and visual information were relatively novel. In $B$, by contrast, a fourth head direction cell established its head direction preference predominantly on the basis of visual cues. If the rat was placed within familiar cues, regardless of the route of entry, the head direction preference remained constant. The directional preference was observed to change only when the rat was exposed to the novel set of visual cues, again irrespective of the route of entry.

rection cells were the same as those observed during standard maze trials. If, on the other hand, both visual and idiothetic information were novel, the directional preferences changed.

The fourth head direction cell tested appeared more visually dependent than the three cells described above (Figure 10B). That is, if the rat entered the room with novel cues, the head direction preference shifted by $90^{\circ}$ regardless of whether the rat experienced a direct or circuitous route. Similarly, the directional preference of the 
cell remained unchanged relative to baseline trials when the rat entered the room with familiar cues, irrespective of the particular route taken to the maze room. For the head direction cells shown in Figure 10, it is unclear why the mean firing rate in the preferred direction varied with test condition since the variations were not systematically related to the specific manipulation.

Novel room test. For comparison with the tests of novel environments just described, animals were also carried into a novel room that contained a different eightarm radial maze surrounded by novel visual cues. In all cases ( $n=5$ cells recorded from 4 rats) the cells remained head directional in terms of their behavioral correlates. However, the directional preference observed in the novel room was always rotated by $90^{\circ}-180^{\circ}$ relative to the absolute directional preference displayed in the familiar room. Figure 4 illustrates the response of two head direction cells that were recorded simultaneously. Given that this recording was the only one with more than one head direction cell, it remains unknown whether the population of head direction cells would remain aligned as an animal moves from one environment to another.

Effects of reward magnitude shifts. As with location cells, it was of interest to determine whether changes in the reward expectations would influence striatal head direction cell-firing properties. Seven cells were tested from 6 rats as described above for the location cells. None of the cells showed any indication of changes in directional preference, directional selectivity, or firing rates in response to the reward shift (all $p \mathrm{~s}>.10$ ).

\section{Simultaneously Recorded Location and \\ Head Direction Cells in Dorsal Striatum}

On four occasions (involving 4 rats), multiple location and head direction cells were recorded simultaneously. One of these sessions included a pair of head direction cells and one location cell (shown in Figure 4). A second session involved one head direction cell and one location cell (shown in Figure 6). The other session (54024) included three head direction cells and two location cells. Figure 10 illustrates another simultaneous recording of location and head direction cells. In all recording sessions, the dissociation between location and head direction cell responses to darkness was evident: Location fields were more readily disrupted by performance in darkness, while head directional firing was still clearly evident despite occasional and transient shifts in directional preference. This differential response of location and head direction cells was also observed with simultaneously recorded head direction and location cells, indicating that the differential responses of location and head direction cells to imposed darkness did not reflect differences in cognitive strategy used to solve the maze by different animals, or differences in perceptual, motor, or motivational variables when recording location and head direction cells.

\section{DISCUSSION}

Spatially correlated discharge was evaluated for neurons of the dorsomedial striatum of rats while they performed a spatial working memory task. Like Wiener (1993), we found spatial cells that discharged relative to an animal's location and/or heading direction on the maze. Furthermore, we verified that striatal location fields in general tend to be of low yet reliable spatial resolution. However, we also found several examples of striatal units with highly distinctive location fields of the sort found in hippocampus. Both striatal location and head direction cells were sensitive to changes in visual context, although they exhibited their sensitivity in different ways.

\section{Location-Specific Discharge in Dorsomedial Striatum}

When the rats performed standard maze trials (with the room lights on), striatal location cells showed many of the same baseline properties that have been reported for hippocampal place cells (e.g., Barnes et al., 1990; Knierim et al., 1995; McNaughton, Barnes, \& O'Keefe, 1983; Mizumori et al., 1996; Mizumori et al., 1989; Mizumori et al., 1992). For example, indicators of the spatial distinctiveness of location fields (e.g., spatial specificity and information content) showed values within the range observed for hippocampal place neurons, although the population mean was lower. Also, the reliability of a given location field was comparable to that reported for hippocampal neurons.

As is the case for hippocampal place fields, striatal location fields probably do not reflect a motor response per se. The locations of the fields did not show consistent relationships to distinct features of the maze architecture (e.g., arm entrances) or to specific motor acts (e.g., turning) in this highly practiced task. Also, the rats were not observed to pause or groom in the vicinity of a location field. Finally, there was no relationship between the velocity of movement on maze arms that contained a location field and the velocity of movement as the rat traversed other maze arms.

Although reward correlates have frequently been reported for primate striatal neurons (e.g., Schultz, Dayan, \& Montague, 1997), this factor seemed to influence only a small number of location cells in this study. In about $91 \%$ of the cells tested, we did not observe a change in location-specific firing when the expected locations of different magnitudes of reward were changed. In contrast, nonspatial reward-related striatal cells recorded from the same rats used in this study frequently altered their firing properties when expected reward magnitudes were varied (Mizumori, Pratt, \& Ragozzino, 1999). In general, then, the location-specific firing of striatal location cells could not be clearly attributed to reward aspects of the task.

Rather than reflecting motor or reward information, the cells classified as location cells appear to process vi- 
sual information concerning the extramaze environment. This is supported by the finding that $15 / 18$ location cells tested showed clear, immediate, and long-lasting changes in firing patterns when the rat was tested in darkness (light-dark-light test). Also, one location cell exhibited a field that changed consistent with the rotation of cues. That some striatal location fields may not be mere reflections of the current visual environment, however, was suggested during the restoration phase of the light-darklight test. Although the location fields changed quickly when the lights were turned off, they occasionally took many trials to restore when the lights were turned back on. The rather immediate response to darkness stands in contrast to the finding that a majority of hippocampal place cells have fields that persist when the lights are turned off (see, e.g., McNaughton, Leonard, \& Chen, 1989; Mizumori, Ragozzino, et al., 1999; Quirk, Muller, $\&$ Kubie, 1990). Therefore, while striatal location fields appear similar to hippocampal place fields in many respects, striatal location cells are clearly more sensitive to changes in visual context. Perhaps this reflects a preferential need to continuously update striatal computations regarding the current visual context (see further discussion below).

\section{Head Direction Discharge in Striatum}

As was the case for the striatal location cells, there was no evidence that the firing of head direction cells reflected a specific motor act during performance in standard light conditions. There was no consistent relationship between movement velocity and unit firing rates. Also, directional discharge was observed irrespective of the specific behaviors of the rat. Directional discharge was observed at such times as when the rat was moving forward along a maze arm, turning at the arm ends or on the maze center, being held by the experimenter as he/ she passively moved the animal from place to place on the maze, or when the rat was sitting still on the maze. Head direction firing probably does not reflect reward information per se since such firing was undisturbed by changes in the locations of the expected reward, and since directional firing was maintained during behavioral manipulations that were not rewarded (e.g., passive movement).

In contrast to the response of striatal location cells, striatal head direction cells rarely showed dramatic, longlasting changes in firing characteristics during the dark phase of the light-dark-light test. These cells, however, often (but not always) showed an initial, transient disruption during dark trials. When animals were carried into the test room in darkness, relatively minor deviations of the preferred direction were sometimes observed (e.g., $45^{\circ}$ shifts in preference). In other cases, the directional preferences appeared normal. In all cases, however, the firing rates remained directionally specific in darkness. Since the head direction correlates did not show dramatic changes in darkness, we tested whether head direction firing reflects visual processing under standard light conditions. Several lines of evidence suggest that the an- swer is yes. First, the results of cue rotations showed that in all cases tested, the preferred direction of head direction cells rotated in accordance with the cues. Second, a transient disruption during dark trials may indicate that during previous light trials, at least a subpopulation of head direction cells utilized visual information to some extent. However, since the original directional preference and selectivity was frequently observed to return with continued exposure to dark trials, the head direction system may readily adapt to altered sensory configurations. Third, maze/rat rotations in a lighted room had no effect on the directional preferences of head direction cells. Finally, when tested in light conditions, disrupting idiothetic cue computations by picking up a rat and passively moving it to its first of eight choices did not affect directional firing.

It appears, then, that striatal head direction cells are influenced predominantly by visual cues in light, and yet can be guided by nonvisual cues in darkness. Under different test situations, a similar phenomenon has been shown for limbic head direction cells (e.g., Blair \& Sharp, 1996; Goodridge \& Taube, 1995). The results of maze/ rat rotations and passive movement tests carried out in darkness in the present study suggest that idiothetic, rather than intramaze, information maintains the directional information in darkness. Both manipulations produced clear changes in the directional properties of these cells when performed in darkness, but not in light conditions. Also, the degree of rotation of the directional preferences was not predicted by the degree of rotation of the maze/ rat in darkness.

The conditional use of visual and idiothetic information was also suggested by the results of varying the route by which animals were transported from the animal colony room to a familiar maze room. If the rat was carried in a covered container along the normal (direct) route, the directional preferences of the head direction cells were not affected whether the maze was surrounded by familiar or novel cues. On the other hand, when the same rat was carried along a novel, circuitous route (also in a covered container), the directional preferences changed only when new cues were presented in the otherwise familiar test room. Circuitous route entry into the maze room with familiar cues did not affect the baseline directional preferences. Thus, if either familiar visual or familiar idiothetic information was available, the directional preferences of the head direction cells were the same as those observed during standard maze trials. If, on the other hand, both visual and idiothetic information were novel, the directional preferences changed. The combined results of the various manipulations performed on the striatal head direction cells of this study suggest a capacity to adapt rather quickly to changing environmental demands by flexibly using the appropriate, most reliable sensory configuration to solve a task. A mechanism of flexibility such as this could greatly facilitate behavioral or cognitive strategy selection by structures afferent to striatum. 


\section{Contribution of Dorsal Striatum to Adaptive Spatial Navigation}

The results of this study are consistent with a view that the striatal location and head direction cells are functionally connected to the limbic navigation system. In many, but not all, respects, striatal location cells resembled hippocampal place cells: Spatial specificity and reliability appear comparable, and both populations are sensitive (although in different ways) to changes in the visual spatial environment. Also, there were important similarities between striatal and anterior thalamic (Taube, 1995a) head direction cell properties. In both structures, the head direction cells may contribute to an internally guided spatial knowledge system that allows organisms to be aware of their general orientation in a familiar environment despite a sudden and drastic reduction in external sensory input. In contrast, lateral dorsal thalamic head direction representations are more sensitive to imposed darkness (Mizumori \& Williams, 1993), indicating that the LDN head direction system is guided more by current visual information.

Striatal location cells may correspond to the population of spiny neurons (Wiener, 1993). Both are relatively abundant, and both have very low baseline firing rates. Dorsal striatal GABAergic interneurons, on the other hand, exhibit physiological properties that parallel those of dorsal striatum head direction cells. Both show rapid, high-frequency responses followed by an ability to sustain high firing rates. Discharge offset can be equally as abrupt as discharge onset (Kawaguchi, 1993). Since GABAergic interneurons and spiny neurons receive primarily cortical input (Dube, Smith, \& Bolam, 1988; Fonnum, Storm-Mathisen, \& Divac, 1981), striatal location and directional codes may receive specific location or directional instruction from structures known to represent similar information, such as retrosplenial (Chen, Lin, Barnes, \& McNaughton, 1994; Chen, Lin, Green, et al., 1994) or entorhinal cortex (Mizumori et al., 1992; Quirk, Muller, Kubie, \& Ranck, 1992). Indeed, the anatomical location at which striatal head direction cells were recorded coincides with the location of retrosplenial and entorhinal cortical innervation (McGeorge \& Faull, 1989).

It is important to point out that although the dorsal striatum may act within a larger neural network during spatial context learning, the dorsal striatum may also make unique contributions to response learning. The distinct contribution to response learning may reflect the somatotopically organized sensory and motor representations in the lateral dorsal striatum (see, e.g., Donoghue \& Kitai, 1981; McGeorge \& Faull, 1989) rather than a unique intrastriatal computational architecture. In contrast, the medial aspect of dorsal striatum, by virtue of its limbic connections, may be preferentially used during adaptive navigation. Spatial context information could arrive in dorsal striatum via direct connections with entorhinal cortex (Swanson \& Kohler, 1986), perirhinal cortex (Burwell, Witter, \& Amaral, 1995; McGeorge \& Faull, 1989), and subiculum (Groenewegen, Vermeulan-
Van der Zee, te Kortschot, \& Witter, 1987). When the dorsomedial striatum is lesioned, other pathways (e.g., CA1 or entorhinal cortex to frontal cortex, Amaral \& Witter, 1995; Jay \& Witter, 1991) might compensate for the lesion during spatial learning in such a way that deficits may not always be observed. Such compensation may not be possible during response learning because of the comparatively restricted circuitry mediating accurate performance. Consequently, deficits in response learning are reliably observed following (lateral) striatal lesions.

The striatum may make special contributions to navigation due to the unique bistable membrane condition of medium spiny striatal neurons. This cellular property may contribute to highly selective spatial information processing within dorsal striatum. The "down state" of this potential is caused by a massive inwardly rectifying potassium current that serves as a shunt for weak or asynchronous inputs. Transitions between states are regulated by the temporal and spatial pattern of excitatory afferents (Wilson, 1993), presumably derived from broad areas of cortex (Cowan \& Wilson, 1994). Perhaps this cortical input is one mechanism by which association areas of cortex can inform the dorsal striatum about environmental conditions (i.e., context) in which behavioral acts occur. Since behavior is continuous, it may be necessary for striatum to receive continual updates of the current spatial context. This information, together with input concerning an animal's movement, orientation in space, and currently experienced reinforcement contingencies, could allow for direct modification of spiny neuron output.

Our findings are consistent with the view that the basal ganglia encourage, rather than discourage, behavioral flexibility (see, e.g., Graybiel \& Kimura, 1995; Wise et al., 1996). Accordingly, the basal ganglia serve to integrate internal (i.e., motivational) and external (i.e., sensory) contextual information with the development of the appropriate action patterns via elaborate interconnections with frontal cortex. We recently extended this view by hypothesizing that dorsal striatum may evaluate whether an expected response outcome occurs as predicted by a particular context (Mizumori, Pratt, \& Ragozzino, 1999). If expected response outcomes do not occur, dorsal striatum can update spatial memory representations in cortex accordingly (Middleton \& Strick, 1996) in addition to changing the probability of the selection of a future cognitive/response strategy by frontal cortex (Winocur \& Eskes, 1998; Wise et al., 1996). In effect, striatum helps to define the goals of future actions, thereby facilitating behavioral accuracy.

Our understanding of spatial navigation has been steadily maturing in recent years (e.g., Burgess, Recce, \& O'Keefe, 1994; Eichenbaum, 1996; McNaughton et al., 1996; Mizumori, 1994; Mizumori et al., 1996; Muller, Stead, \& Pach, 1996; Poucet \& Benhamou, 1997; Sharp, Blair, \& Brown, 1996; Tanila, 1999; Taube, Goodridge, Golob, Dudchenko, \& Stackman, 1996; Wiener, 1996). The focus of current theories is typically on the role of 
hippocampal place cells and head direction cells of limbic thalamus and neocortex. Lavoie and Mizumori (1994), and more recently Sharp et al. (1996) and Redish and Touretsky (1997), postulated that the ventral striatum might integrate limbic spatial information with reinforcement consequences to regulate behavioral navigation. Mizumori, Pratt, and Ragozzino (1999) and the present data expand this notion to include dorsal striatum. This study suggests that an important function of the dorsal striatum may be to provide continuity in behavioral performance across changing environment when animals may switch between cognitive strategies. Indeed, it has been suggested that animals readily switch between landmark- and route-based strategies as they navigate their environment (Benhamou, 1996; M. F. Brown \& Bing, 1997; Gallistel, 1990; Gothard, Skaggs, Moore, \& McNaughton, 1996; Maaswinkel \& Whishaw, 1999). In many cases, a strategy switch is thought to occur between visually distinct, experience-defined contexts. Dorsal striatum may coordinate this sort of adaptive behavioral planning in conjunction with neocortex.

\section{REFERENCES}

Alexander, G. E., \& Crutcher, M. D. (1990). Neural representations of the target (goal) of visually guided arm movements in three motor areas of the monkey. Journal of Neurophysiology, 64, 164-178.

Amaral, D. G., \& WitTer, M. P. (1995). Hippocampal formation. In G. Paxinos (Ed.), The rat nervous system (2nd ed., pp. 443-493). San Diego: Academic Press.

Arnauld, E., Jeantet, Y., Arsaut, J., \& Demotes-Mainard, J. (1996). Involvement of the caudal striatum in auditory processing: $c$-fos response to cortical application of picrotoxin and to auditory stimulation. Molecular Brain Research, 41, 27-35.

BARNeS, C. A. (1988). Spatial learning and memory processes: The search for their neurobiological mechanisms in the rat. Trends in Neurosciences, 11, 163-169.

Barnes, C. A., McNaughton, B. L., Mizumori, S. J. Y., Leonard, B. W., \& LiN, L. H. (1990). Comparison of spatial and temporal characteristics of neuronal activity in sequential stages of hippocampal processing. Progress in Brain Research, 83, 287-300.

Barnes, C. A., Suster, M. S., Shen, J., \& MCNaughton, B. L. (1997). Multistability of cognitive maps in the hippocampus of old rats. $\mathrm{Na}$ ture, 388, 272-275.

Benhamou, S. (1996). No evidence for cognitive mapping in rats. $A n$ imal Behaviour, 52, 201-212.

BLAIR, H. T., \& SHARP, P. E. (1996). Visual and vestibular influences on head direction cells in the anterior thalamus of the rat. Behavioral Neuroscience, 110, 643-660.

Brown, L. L., Feldman, S. M., Divac, I., Hand, P. J., \& Lidsky, T. I. (1994). A distributed network of context-dependent functional units in the rat neostriatum. In G. Percheron, J. S. McKenzie, \& J. Feger (Eds.), The basal ganglia IV: New ideas and data on structure and function (Advances in Behavioral Biology, Vol. 41, pp. 215-227). New York: Plenum.

Brown, L. L., Hand, P. J., \& Divac, I. (1996). Representation of a single vibrissa in the rat neostriatum: Peaks of energy metabolism reveal a distributed functional module. Neuroscience, 75, 717-728.

Brown, M. F., \& BiNG, M. N. (1997). In the dark: Spatial choice when access to spatial cues is restricted. Animal Learning \& Behavior, 25, $21-30$.

Burgess, N., Recce, M., \& O’ Keefe, J. (1994). A model of hippocampal function. Neural Networks, 7, 1065-1081.

Burwell, R. D., Witter, M. P., \& Amaral, D. G. (1995). The perirhinal and postrhinal cortices of the rat: $A$ review of the neuro- anatomical literature and comparisons with findings from the monkey brain. Hippocampus, 5, 390-408.

Chen, L. L., Lin, L.-H., Barnes, C. A., \& McNaughton, B. L. (1994) Head-direction cells in the rat posterior cortex: II. Contributions of visual and ideothetic information to the directional firing. Experimental Brain Research, 101, 24-34.

Chen, L. L., Lin, L.-H., Green, E. J., Barnes, C. A., \& McNaughton, B. L. (1994). Head-direction cells in the rat posterior cortex: I. Anatomical distribution and behavioral modulation. Experimental Brain Research, 101, 8-23.

COOK, D., \& KesNer, R. P. (1988). Caudate nucleus and memory for egocentric localization. Behavioral \& Neural Biology, 49, 332-343.

Cools, A., van den Bercken, J. H. L., Horsink, M. W. I., van SpaenDONCK, K. P. M., \& BERGER, H. J. C. (1984). Cognitive and motor shifting aptitude disorder in Parkinson's disease. Journal of Neurology \& Neurosurgical Psychiatry, 47, 443-453.

CoOper, B. G., MiYA, D. Y., \& Mizumori, S. J. Y. (1998). Behavioral correlates of superior colliculus neuron discharge during active navigation by rats. Hippocampus, 8, 340-372.

COWAN, R. L., \& WILSON, C. J. (1994). Spontaneous firing patterns and axonal projections of single corticostriatal neurons in the rat medial agranular cortex. Journal of Neurophysiology, 71, 17-32.

Crutcher, M. D., \& Alexander, G. E. (1990). Movement-related neuronal activity selectively coding either direction or muscle pattern in three motor areas of the monkey. Journal of Neurophysiology, 64, 151-163.

Devan, B. D., Goad, E. H., \& Petri, H. L. (1996). Dissociation of hippocampal and striatal contributions to spatial navigation in the water maze. Neurobiology of Learning \& Memory, 66, 305-323.

Devan, B. D., McDonald, R. J., \& White, N. M. (1999). Effects of medial and lateral caudate-putamen lesions on place- and cue-guided behaviors in the water maze: Relation to thigmotaxis. Behavioural Brain Research, 100, 5-14.

Devan, B. D., \& WhITE, N. M. (1999). Parallel information processing in the dorsal striatum: Relation to hippocampal function. Journal of Neuroscience, 19, 2789-2798.

Divac, I., Markowitsch, H. J., \& Pritzel, M. (1978). Behavioral and anatomical consequences of small intrastriatal injections of kainic acid in the rat. Brain Research, 151, 523-532.

Divac, I., Rosvold, E., \& Szwarcbart, M. K. (1967). Behavioral effects of selective ablation of the caudate nucleus. Journal of Comparative \& Physiological Psychology, 63, 184-190.

Donoghue, J. P., \& KITAI, S. T. (1981). A collateral pathway to the neostriatum from corticofugal neurons of the rat sensory-motor cortex: An intracellular study. Journal of Comparative Neurology, 201, 1-13.

Downes, J. J., Roberts, A. C.. Sahakian, B. J., Evenden, J. L., MorRIS, R. G., \& RoBBins, T. W. (1989). Impaired extra-dimensional shift performance in medicated and unmedicated Parkinson's disease: Evidence for a specific attentional dysfunction. Neuropsychologia, 27, 1329-1343

Dube, L., Smith, A. D., \& Bolam, J. P. (1988). Identification of synaptic terminals of thalamic or cortical origin in contact with distinct medium-size spiny neurons in the rat neostriatum. Journal of Comparative Neurology, 267, 455-471.

DUNNETT, S. B., \& IVERSEN, S. D. (1982). Sensorimotor impairments following localized kainic acid and 6-hydroxydopamine lesions of the neostriatum. Brain Research, 248, 121-127.

Eichenbaum, H. (1996). Is the rodent hippocampus just for "place"? Current Opinions in Neurobiology, 6, 187-195.

Fonnum, F., Storm-Mathisen, J., \& Divac, I. (1981). Biochemical evidence for glutamate as neurotransmitter in corticostriatal and corticothalamic fibres in rat brain. Neuroscience, 6, 863-873.

Gallistel, C. R. (1990). The organization of learning. Cambridge, MA: MIT Press.

GaRdinER, T. W., \& Kital, S. T. (1992). Single-unit activity in the globus pallidus and neostriatum of the rat during performance of a trained head movement. Experimental Brain Research, 88, 517-530.

GoOdRidge, J. P., \& TAUBe, J. S. (1995). Preferential use of the landmark navigational system by head direction cells in rats. Behavioral Neuroscience, 109, 49-61. 
Gothard, K. M., Skaggs. W. E.. Moore, K. M., \& McNaughton, B. L. (1996). Binding of hippocampal CAl neural activity to multiple reference frames in a landmark-based navigation task. Journal of Neuroscience, 16, 823-835.

Graybiel, A. M., \& Kimura, M. (1995). Adaptive neural networks in the basal ganglia. In J. C. Houk, J. L. Davis, \& D. G. Beiser (Eds.), Models of information processing in the basal ganglia (pp. 103-116). Cambridge, MA: MIT Press.

Groenewegen, H. J., \& Berendse. H. W. (1994). Anatomical relationships between the prefrontal cortex and the basal ganglia in the rat. In A. M. Thierry, J. Glowinski, P. S. Goldman-Rakic, \& Y. Christen (Eds.), Motor and cognitive functions of the prefrontal cortex (pp. 51-77). Berlin: Springer-Verlag.

Groenewegen, H. J., Vermeul.an-Van der Zee, E., te Kortschot, A., \& WitTER. M. P. (1987). Organization of the projections from the subiculum to the ventral striatum in the rat: A study using anterograde transport of Phaseolus vulgaris-leucoagglutinin. Neuroscience, 23, 103-120.

JAY, T. M., \& WITTER, M. P. (1991). Distribution of hippocampal CAI and subicular efferents in the prefrontal cortex of the rat studied by means of Phaseolus vulgaris-leucoagglutinin. Journal of Comparative Neurology, 313, 574-586.

HaUber, W., \& SChmidt, W. J. (1994). Differential effects of lesion of the dorsomedial and dorsolateral caudate-putamen on reaction time performance in rats. Behavioral Brain Research, 60, 211-215.

HaYs, W. L. (1994). Statistics (5th ed.). Orlando, FL: Harcourt Brace.

Hetherington, P. A., \& Shapiro, M. L. (1997). Hippocampal place fields are altered by the removal of single visual cues in a distancedependent manner. Behavioral Neuroscience, 111, 20-34.

Hikosaka, O.. Sakamoto. M.. \& Usui, S. (1989). Functional properties of monkey caudate neurons: III. Activities related to expectation of target and reward. Journal of Neurophysiology, 61, 814-832.

Hikosaka, O., \& WURTZ, R. H. (1983). Visual and oculomotor functions of monkey substantia nigra pars reticulata: III. Memory-contingent visual and saccade responses. Journal of Neurophvsiologv, 49, 1268-1284.

KaWAGUCHI, Y. ( 1993). Physiological, morphological and histochemical characterization of three classes of interneurons in rat neostriatum. Journal of Neuroscience, 13, 4908-4923.

Kesner, R. P., Bolland, B. L., \& Dakis, M. (1993). Memory for spatial locations, motor responses, and objects: Triple dissociation among the hippocampus, caudate nucleus. and extrastriate visual cortex. Experimental Brain Research, 93, 462-470.

KimURA. M. (1990). Behaviorally contingent property of movementrelated activity of the primate putamen. Journal of Neurophysiology, 63, 1277-1296.

Knierim. J. J., Kudrimoti, H. S., \& McNaughton, B. L. (1995). Place cells, head direction cells, and the learning of landmark stability. Journal of Neuroscience, 15, 1648-1659.

KuBie, J. L., Muller, R. U., \& Bostock, E. (1990). Spatial firing properties of hippocampal theta cells. Journal of Neuroscience, $\mathbf{1 0}$, 1110-1123.

Lavoie, A. M., \& Mizumorı, S. J. Y. (1994). Spatial-, movement-, and reward-sensitive discharge by medial ventral striatum neurons of rats. Brain Research. 638, 157-168.

Levy, R., Friedman, H. R., Davachi, L., \& Goldman-Rakic, P. S. (1997). Differential activation of the caudate nucleus in primates performing spatial and nonspatial working memory tasks. Journal of Neturoscience, 17. 3870-3882.

MaASWINKEL, H.. \& WhiShaW, I. Q. (1999). Homing with locale, taxon, and dead reckoning strategies by foraging rats: Sensory hierarchy in spatial navigation. Behavioural Brain Research, 99, 143-152.

Maguire, E. A., Burgess, N., Donnett, J. G., Frackowiak. R. S. J., FRITH. C. S., \& O'KeEFE. J. (1998). Knowing where and getting there: A human navigation network. Science, 280, $921-924$

Markus, E. T., Barnes, C. A., McNaughton, B. L., Gladden, V. L.. \& SKagGS, W. E. (1994). Spatial information content and reliability of hippocampal CAI neurons: Effects of visual input. Hippocampus. 4, 410-421.

Markus, E. J., Qin, Y. L., Leonard, B., Skaggs, W. E., Mc Naughton, B. L., \& BARNES, C. A. (1995). Interactions between location and task affect the spatial and directional firing of hippocampal neurons. Journal of Neuroscience, 15, 7079-7094.

MCGEORGE, A. J., \& FAULL, R. L. M. (1989). The organization of the projection from the cerebral cortex to the striatum in the rat. Neuroscience, 29, 503-537.

McNaughton, B. L., Barnes, C. A., Gerrard, J. L., Gothard, K. Jung, M. W., Knierim, J. J., Kudrimoti, H., Qin, Y., Skaggs, W. E. SUSTER, M., \& Weaver. K. L. (1996). Deciphering the hippocampal polyglot: The hippocampus as a path integration system. Journal of Experimental Biology, 199. 173-185.

McNaughton, B. L., Barnes, C. A.. \& O'Keefe, J. (1983). The contributions of position, direction and velocity to single unit activity in the hippocampus of freely-moving rat. Experimental Brain Research, 52, 41-49.

MCNaughton, B. L., Leonard, B., \& Chen, L. (1989). Corticalhippocampal interactions and cognitive mapping: A hypothesis based on reintegration of parietal and inferotemporal pathways for visual processing. Psychobiology, 17, 236-246.

MCNaughton, B. L., O'Keefe, J., \& Barnes, C. A. (1983). The stereotrode: A new technique for simultaneous isolation of several single units in the central nervous system from multiple unit records. Journal of Neuroscience Methods, 8, 391-397.

Middleton, F. A., \& Strick, P. L. (1996). The temporal lobe is a target output from the basal ganglia. Proceedings of the National Academy of Sciences, 93, 8683-8687.

MizumoRı, S. J. Y. (1994). Neural representations during spatial navigation. Current Directions in Psychological Science, 3, 125-129.

Mizumori, S. J. Y., Lavoie, A., \& Kalyani, A. (1996). Redistribution of spatial representation in the hippocampus of aged rats performing a spatial memory task. Behavioral Neuroscience, 110, 1006-1016.

Mizumori. S. J. Y., McNaughton, B. L., Barnes, C. A., \& Fox, K. B (1989). Preserved spatial coding in hippocampal CAl pyramidal cells during reversible suppression of $\mathrm{CA} 3$ output: Evidence for pattern completion in hippocampus. Journal of Neuroscience, 9, 3915-3928.

Mizumori, S. J. Y., Perez, G. M., Alvarado, M. C., Barnes, C. A., \& MCNAUGHTON, B. L. (1990). Reversible inactivation of the medial septum differentially affects two forms of learning in rats. Brain Research, 528, 12-20.

Mizumori, S. J. Y., Pratt, W. E., \& Ragozzino, K. E. (1999). Functions of the nucleus accumbens within the context of the larger striatal system. Psychobiology, 27, 214-224.

Mizumori, S. J. Y., Ragozzino, K. E., Cooper. B. G., \& Leutgeb, S (1999). Hippocampal representational organization and spatial context. Hippocampus, 9, 444-451.

Mizumori, S. J. Y., Ward. K. E., \& Lavoie, A. M. (1992). Medial septal modulation of entorhinal single unit activity in anesthetized and freely moving rats. Brain Research. 570, 188-197.

MizumoRI, S. J. Y., \& WILLIAMS, J. D. (1992). Interdependence of hippocampal and lateral dorsal thalamic representations of space. Society for Neuroscience Abstracts, 18, 708 .

MizumoRI, S. J. Y., \& WiLliams, J. D. (1993). Directionally-selective mnemonic properties of neurons in the lateral dorsal nucleus of the thalamus of rats. Journal of Neuroscience, 13, 4015-4028.

Muller, R. U., Stead, M., \& PaCh, J. (1996). The hippocampus as a cognitive graph. Journal of General Physiology, 107, 663-694.

PAxinos, G.. \& WATSON. C. (1986). The rat brain in stereotaxic coordinates. Sydney, Australia: Academic Press.

PouceT, B., \& Benhamou, S. (1997). The neuropsychology of spatial cognition in the rat. Critical Reviews in Neurobiology, 11, 101-120.

PRatr, W. E., \& Mizumori, S. J. Y. (1998). Characteristics of basolateral amygdala neuronal firing on a spatial memory task involving differential reward. Behavioral Neuroscience, 112, 554-570.

Quirk, G. J., MULler, R. U., \& KuBIE. J. L. (1990). The firing of hippocampal place cells in the dark depends on the rat's recent experience. Journal of Neuroscience, 10, 2008-2017.

Quirk, G. J., Muller, R. U.. Kubie, J. L., \& RanCK, J. B., JR. (1992), The positional firing properties of medial entorhinal neurons: Description and comparison with hippocampal place cells. Journal of Neuroscience, 12, 1945-1963.

Ri.ading, P. J., Dunnett. S. B.. \& Robbins, T. W. (1991). Dissociable 
roles of the ventral, medial, and lateral striatum on the acquisition and performance of a complex visual stimulus-response habit. Behavioural Brain Research, 45, 147-161.

ReDish, A. D., \& TouretzKy, D. S. (1997). Cognitive maps beyond hippocampus. Hippocampus, 7, 15-35.

Rolls, E. T., ThORPE, S. J., \& MADDison, S. P. (1983). Responses of striatal neurons in the behaving monkey: I. Head of the caudate nucleus. Behavioural Brain Research, 7, 179-210.

Schultz, W., Apicella, P., Romo, R., \& SCarnati, E. (1995). Contextdependent activity in the primate striatum reflecting past and future behavioral events. In J. C. Houk, J. L. Davis, \& D. G. Beiser (Eds.), Models of information processing in the basal ganglia (pp. 11-27). Cambridge, MA: MIT Press.

Schultz, W., Dayan, P., \& Montague, P. R. (1997). A neural substrate of prediction and reward. Science, 275, 1593-1 599.

SCHultz, W., \& Romo, R. (1992). Role of primate basal ganglia and frontal cortex in the internal generation of movements: Comparison with instruction-induced preparatory activity in striatal neurons. $E x$ perimental Brain Research, 91, 363-384.

Sharp, P. E., Blair, H. T., \& Brown, M. (1996). Neural network modeling of the hippocampal formation spatial signals and their possible role in navigation: A modular approach. Hippocampus, 6, 720-734.

Sharp, P. E., Blair, H. T., Etkin, D., \& Tzanetos, D. B. (1995). Influences of vestibular and visual motion information on the spatial firing patterns of hippocampal place cells. Journal of Neuroscience, 15, 173-189.

Silver, P. H. (1967). Spectral sensitivity of the white rat by a training method. Vision Research, 7, 377-383.

Skaggs, W. E., McNaughton, B. L., Gothard, K. M., \& Markus, E. J. (1993). An information-theoretic approach to deciphering the hippocampal code. In S. J. Hanson, J. D. Cowan, \& C. L. Giles (Eds.), Advances in neural information processing systems (pp. 1030-1037). San Mateo, CA: Kaufman.

SWANSON, L. R. (1992). Brain maps: Structure of the rat brain. Amsterdam: Elsevier.

Swanson, L. R., \& KoHLER, C. (1986). Neuroanatomical evidence for direct projections from the entorhinal area to the entire cortical mantle in the rat. Journal of Neuroscience, 6, 3010-3023.

TANILA, H. (1999). Hippocampal place cells can develop distinct representations of two visually identical environments. Hippocampus, 9. 235-246.
Tanila, H., Shapiro, M., Gallagher, M., \& Eichendaum, H. (1997). Brain aging: Changes in the nature of information coding by the hippocampus. Journal of Neuroscience, 17, 5155-5166.

TAUBE, J. S. (1995a). Head direction cells recorded in the anterior thalamic nuclei of freely moving rats. Journal of Neuroscience, 15, 70-86.

TAUBE, J. S. (1995b). Place cells recorded in the parasubiculum of freely moving rats. Hippocampus, 5, 569-583.

Taube, J. S., Goodridge, J. P., Golob, E. J., Dudchenko, P. A., \& Stackman, R. W. (1996). Processing the head direction cell signal: A review and commentary. Brain Research Bulletin, 40, 477-486.

Taube, J. S., Muller, R. U., \& Ranck, J. B., JR. (1990). Head direction cells recorded from the postsubiculum in freely moving rats: I. Description and quantitative analysis. Journal of Neuroscience, 10 , 420-435.

Tremblay, L., Hollerman, J. R., \& Schultz, W. (1998). Modifications of reward expectation-related neuronal activity during learning in primate striatum. Journal of Neurophysiology, 80, 964-977.

Whishaw, I. Q., Mittleman, G., Bunch, S. T., \& Dunnett, S. B. (1987). Impairments in the acquisition, retention and selection of spatial navigation strategies after medial caudate-putamen lesions in rats. Behavioural Brain Research, 24, 125-138.

WIENER, S. I. (1993). Spatial and behavioral correlates of striatal neurons in rats performing a self-initiated navigation task. Journal of Neuroscience, 13, 3802-3817.

WIENER, S. I. (1996). Spatial, behavioral and sensory correlates of hippocampal CAI complex spike cell activity: Implications for information processing functions. Progress in Neurohiology, 49, 335-361.

Wiener, S. I., Korshunov, V. A., Garcia, R., \& Berthoz, A. (1995). Inertial, substratal and landmark cue control of hippocampal CA 1 place cell activity. European Journal of Neurosciencee, 7, 2206-2219.

WILSON, C. J. (1993). The generation of natural firing patterns in neostriatal neurons. Progress in Brain Research, 88, 277-297.

Winocur, G., \& Eskes, G. (1998). Prefrontal cortex and caudate nucleus in conditional associative learning: Dissociated effects of selective brain lesions in rats. Behavioral Neuroscience, 112, 89-101.

Wise, S. P., MurRay, E. A.. \& Gerfen, C. R. (1996). The frontal cortexbasal ganglia system in primates. Critical Reviews in Neurobiology, 10, 317-356

(Manuscript received April 19, 2000; revision accepted for publication July 14,2000 .) 